\title{
Methodological individualism: True and false
}

\author{
Alexander J. Malt ${ }^{1}$ \\ Published online: 15 December 2016 \\ (C) The Author(s) 2016. This article is published with open access at Springerlink.com
}

\begin{abstract}
I apply Hayek's distinction between 'true' and 'false' individualism to methodological individualism. Hayek traced 'false' individualism to Cartesian rationalism; Hayek's rejection of Mises' praxeology was due to its rationalist underpinnings. The first half of this paper identifies praxeology's foundational philosophical concepts, emphasising their Cartesian nature, and illustrates how together they constitute a case for methodological individualism: intuition and deduction; reductionism; judgement; dualism. In the second half of this paper, I draw upon philosophy and cognitive science to articulate 'Hayekian' (N.B. not Hayek's) alternatives to these Cartesian concepts. The Hayekian alternative allows a 'gestalt switch' from the individual- to the system-level perspective. I therefore suggest that methodological individualism is both true and false: true, in that economic phenomena are grounded in the actions of individuals; false, in that certain problems might be reconceived/discovered at the system-level. I finish by suggesting three avenues of research at system-level: optimisation; stigmergy; computational complexity.
\end{abstract}

Keywords Methodological individualism · Hayek · Cartesian rationalism · Praxeology

JEL B3 $\cdot$ B4 $\cdot$ B5

...the fundamental attitude of true individualism is one of humility toward the processes by which mankind has achieved things which have not been designed or understood by any individual and are indeed greater than individual minds. The great question at this moment is whether man's mind will be allowed to continue to grow as part of this process or whether human reason is to place itself in chains of its own making.

- F. A. Hayek

'Individualism: True and False'

Alexander J. Malt

alexander.j.malt@durham.ac.uk

1 Department of Philosophy, University of Durham, 50 Old Elvet, Durham DH1 3HN, UK 


\section{Introduction}

Hayek (1946) distinguished 'true' and 'false' individualism. False individualism presents a strict 'individual-state' dichotomy, and maintains that social process must be subject to conscious control if they are to serve human ends. True individualism emphasises non-compulsory conventions, and teaches humility toward spontaneous orders which result from human action but not human design. True individualism originated in British philosophy, particularly Scottish Enlightenment thought. By contrast, false individualism derives from Cartesian rationalism. This philosophical distinction led Hayek to criticise Mises for his teacher's "extreme rationalism, which as a child of his time [Mises] could not escape from" - this rationalism, Hayek believed, is "factually mistaken" (1978, xxiii-xxiv).

In this paper I take up Hayek's distinction but focus on methodological individualism. I reconstruct methodological individualism as understood by rationalist philosophy, identifying the foundational philosophical concepts common to both Cartesian rationalism and Misesian praxeology: intuition and deduction; reductionism; judgement; dualism. I then present Hayekian alternatives to these Cartesian concepts: dualism may be dissolved; judgements need not guide action; explanation may proceed at an emergent system-level; economics need not proceed via deduction from intuited first principles, but by identifying and formalising patterns. I argue that the Hayekian alternative enables a gestalt switch between individual and 'system-level' perspectives on economic phenomena. Consequently, methodological individualism is 'true and false': it is true, in that economic phenomena are grounded in the actions of individuals; it is false, in that a system-level perspective allows us to reconceptualise traditional problems and - perhaps - opens new domains of enquiry.

Importantly, this paper should not be understood as attempting to decisively refute Cartesianism or praxeology. ${ }^{1}$ My aim is to identify and oppose the concepts that (consciously or otherwise) shape the Misesian and Hayekian paradigms within Austrian economics. Neither am I concerned to argue that either Mises' or Hayek's (or other variants) is the true version, or 'gold standard', of methodological individualism. It seems extremely unlikely that either paradigm's validity can be established a priori; they must be judged by the fruits they yield. Although I will not (here) use the non-Cartesian concepts to conduct actual research, the final section suggests three new avenues of research: optimisation; stigmergy; computational complexity.

\section{Scientia mirabilis}

In this section I identify core concepts - common to both Cartesian rationalism and praxeology - and illustrate how, taken together, they support a strict methodological individualism. Given both Hayek's opposition of 'true' individualism to that deriving from Cartesian philosophy and his criticism of Mises as maintaining a 'factually mistaken' rationalism, I will initially present these concepts within Descartes'

\footnotetext{
${ }^{1}$ Hülsmann (2006) has different concerns to that of this paper. Hülsmann argues that economics employs counterfactual reasoning (not methodological individualism). I do not believe there to be anything in this paper that necessarily conflicts with Hülsmann's arguments; the two approaches could be taken as complementary.
} 
philosophy (where relevant, these concepts are also linked to work in the cognitive sciences). This enables me (in this section) to parallel lines of reasoning in praxeology and (in the subsequent section) to use Descartes as a foil to present a Hayekian alternative to praxeology.

Three qualifications are necessary. First, characterising these concepts as Cartesian is not to say that particular praxeologists would consciously identify as Cartesians, nor is it to say that these concepts originated with Descartes. ${ }^{2}$ Rather, Descartes presented these concepts extremely forcefully; they continue to shape research today, often without the researchers themselves being aware of this influence. What Hornsby has written of philosophy of mind is analogously true of other disciplines including, I suspect, praxeology:

Philosophers of mind have come to see Cartesian dualism as the great enemy, but have underestimated what they have to contend with. Taking the putatively immaterial character of minds to create the only problem that there is for Descartes' account, they marry up the picture of the person with the picture of her brain, and settle for a view of mind which, though material in its cranial substance, is Cartesian in its essence. $(2006,43)$

Second, as Cottingham observes, 'Cartesianism' "is often used as a label for a variety of doctrines that are so preposterously silly that it can scarcely be a subject of warm selfcongratulation for philosophers to have succeeded in demolishing them" $(2008,76)$. My expositions of Descartes' thought are brief, but I aim to faithfully reconstruct Descartes' views and emphasise his project of creating a 'wonderful science' ('scientia mirabilis'), i.e. a unification of knowledge supported by a metaphysics grounded in self-evident first principles (CSM I, AT X 214). Emphasising the scientific vein of Cartesian philosophy enables links with other disciplines to more easily be seen.

Third, some of these subsections engage in lengthy forays into Cartesian philosophy and other disciplines. The relevance of such discussions might not be immediately obvious, however a detailed discussion of these foundational concepts enables a more stark contrast with the Hayekian alternative in the subsequent section.

\subsection{Intuition and deduction}

Descartes followed Galileo's use of "mathematical methods in the investigations of physical questions", writing that "I am completely at one with [Galileo], for I hold that there is no other way to discover" (CSM III, AT II 380). Galileo maintained:

Philosophy is written in this great book which is continually open before our eyes I mean the universe - but before we can understand it we need to learn the language and recognise the characters in which it is written. It is written in the language of

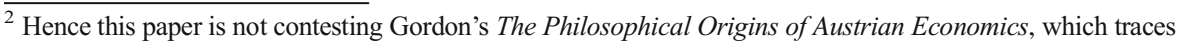
praxeology's roots to Aristotle, via Brentano: "Action, that leitmotif of praxeology, has in the Austrian tradition received a distinctly Aristotelian analysis" (1996, 41; see also Smith 1990). In particular, Gordon traces the deductive method to Aristotle's Posterior Analytics, and Menger's theory of value to Brentano's Psychology from an Empirical Standpoint and its revival of intentionality - which explicitly opposes the 'modern' tradition of epistemology inaugurated by Descartes.
} 
mathematics, and its characters are triangles, circles, and other geometrical figures, without which it is impossible to understand a word of what it says. Without these, it is just wandering aimlessly in a maze. (Galileo 2012, 115)

Descartes' endorsed this mathematisation of nature. He aimed at "a completely new science" that would yield "a general solution of all possible equations involving any sort of quantity, whether continuous or discrete, each according to its nature" (CSM III, AT X 156-7). Solutions should be known with certainty: "we reject all such merely probable cognition and resolve to believe only what is perfectly known and incapable of being doubted" (CSM I, AT X 362). Arithmetic and geometry were the only disciplines that had produced certain knowledge (CSM I, AT X 363), and therefore Descartes envisaged this new science as being akin to arithmetic and geometry. This did not entail that "arithmetic and geometry are the only sciences worth studying"; rather "we ought to concern ourselves only with objects which admit of as much certainty as the demonstrations of arithmetic and geometry" (CSM I, AT X 366 italics mine).

Descartes therefore analysed how the intellect identifies certainties, finding two methods: intuition and deduction (CSM I, AT X 368). Intuition is the intellectual 'perception' of indubitable propositions: "the conception of a clear and attentive mind, which is so easy and distinct that there can be no room for doubt about what we are understanding" (CSM I, AT X 368). By contrast, deduction is

the inference of something as following necessarily from some other propositions which are known with certainty, provided they are inferred from true and known principles through a continuous and uninterrupted movement of thought in which each individual proposition is clearly intuited (CSM I, AT X 369).

A chain of reasoning starting from a self-evident truth and proceeding deductively via a sequence of valid arguments, will produce certain knowledge. ${ }^{3}$

Despite approving of mathematical physics, Descartes criticised Galileo due to the absence of indubitable first principles in the latter's work. According to Descartes, Galileo "does not take time to explain matters fully", "has not investigated in an orderly way, and has merely sought explanations for some particular effects, without going into the primary causes in nature; hence his building lacks a foundation" (CSM III, AT II 380 italics mine). Descartes maintained that "mistakes in the sciences happen... because at the beginning we make judgements too hastily, and accept as our first matters which are obscure and of which we do not have a clear and distinct notion" (CSM II, AT X 526). Consequently, the major concern of Cartesian metaphysics was to produce an indubitable foundation for the new science.

To identify this foundation, Descartes engaged in methodological doubt: By systematically doubting all (sources of) our knowledge, we "make it impossible for us to have any further doubts about what we subsequently discover to be true" (CSM II, AT VII 12). We should therefore "reject all... merely probable cognition and resolve to believe only what is perfectly known and incapable of being doubted" (CSM I, AT X 362).

\footnotetext{
${ }^{3}$ One complication, which I will not pursue here, is that a chain of deductive reasoning involves our memory (CSM I, AT X 370).
} 
Such doubt immediately excludes all propositions known inductively, i.e. those derived from observation and sensory experience. Experience does not present the world to us as it actually is. "Even though we see the sun very clearly," says Descartes, "we must not judge on that account that it is only as large as we see it" (CSM I, AT VI 39-40). Further, as Galileo had already stated, sensory qualities such as tastes, sounds, smells, and colours, "exist only in the mind that perceives them, so that if living creatures were removed, all these qualities would be wiped away and no longer exist" (Galileo 2012, 119). ${ }^{4}$ Descartes concurred, writing that although many people are "convinced that the ideas we have in our mind are wholly similar to the objects from which they proceed" he "cannot see any reason which assures us this is so" and actually made "many observations which should make us doubt it" (CSM I, AT XI 3).

The "greatest benefit" of methodological doubt "lies in freeing us from all our preconceived opinions, and providing the easiest route by which the mind may be led away from the senses" (CSM II, AT VII 12). Methodological doubt reveals that "we ought never to let ourselves be convinced except by evidence of our reason" (CSM I, AT VI 39-40). This accounts for the 'superiority' of arithmetical and geometrical knowledge: "they [arithmetic and geometry] alone are concerned with an object so pure and simple that they make no assumptions that experience might render uncertain; they consist entirely in deducing conclusion by means of rational arguments" (CSM I, AT X 365).

Via methodological doubt, Descartes identified the cogito ('I am thinking'): I cannot doubt that I am thinking because any doubt would be an instance of thought, affirming the very thing I am attempting to doubt (CSM I, AT VI 32-33). The truth of the cogito can be intuited, i.e. perceived directly, and Descartes' would use it as the foundation from which he could proceed to deduce his new science.

Markie (2015), in his exposition of rationalism, therefore identifies the 'intuition/ deduction thesis' as an essential characteristic: "Some propositions in a particular subject area, S, are known to us by intuition alone; still others are knowable by being deduced from intuited propositions" (Markie 2015). Markie also identifies a related (but non-essential) 'superiority of reason' thesis: "The knowledge we gain in subject area S by intuition and deduction... is superior to any knowledge gained by sense experience" (Markie 2015). The superiority thesis is seen in Descartes' arguments (above) that the senses may be deceptive, that we require deduction to make necessary inferences, and that intuition is superior to "the fluctuating testimony of the senses" (CSM I, AT X 368). These positions are reiterated by later rationalists - Leibniz, for example, writes:

Although the senses are necessary for all our actual knowledge, they aren't sufficient to provide it all, because the senses never give us anything other than instances, i.e. particular or singular truths. But however many instances confirm a general truth, they aren't enough to establish its universal necessity; for it needn't be the case that what has happened always will - let alone that it must - happen in the same way...

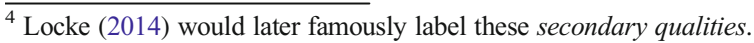


...necessary truths, such as we find in pure mathematics and particularly in arithmetic and geometry, must have principles whose proof does not depend on instances (or, therefore, on the testimony of the senses, even though without the senses it never occurs to us to think of them. (Leibniz 1704, 2-3)

Leibniz continued: "only reason can: establish reliable rules; make up deficiencies of rules that have proved unreliable, by allowing exceptions to them; and lastly, construct necessary inferences, involving unbreakable links" (Leibniz 1704, 3-4).

Both the intuition/deduction and superiority of reason theses inform praxeology in a manner reminiscent of Cartesian rationalism. As Markie notes: "We can generate different versions of the intuition/deduction thesis by substituting different subject areas for the variable S" (Markie 2015). For praxeologists the realms of action, economics, and catallactics are to be substituted for S. Where S denotes praxeology, the 'action axiom' is the intuited foundational assumption, and other propositions are deduced from this axiom. ${ }^{5}$

This axiom states: 'humans act'. Its justification is structurally identical to that of the cogito ${ }^{6}$ :

Denial of the axiom's... validity involves a purposeful act on the part of the skeptics. It therefore confronts them with the uncomfortable choice of either conceding the issue or proclaiming that their own disagreement is purposeless. Thus any denial of the action axiom is self-contradictory (Selgin 1990, 15; see also Hoppe ${ }^{7}$ 1995, 22).

The action axiom is "a self-evident proposition" (Mises 1962, 4): it is neither deduced from some prior proposition nor derived from experience; it is grasped intuitively. It is the foundation from which praxeology proceeds: "All that is needed for the deduction of all praxeological theorems is knowledge of the essence of human action... All the concepts and theories of praxeology are implied in the category of human action" (Mises 1998, 64). Praxeology - "consequently economics too" - is a deductive discipline (Mises 1998, 68) proceeding from, or "expounding the contents" of, the action axiom (Mises 1962, 8; see also Rothbard 2009, 2; Rothbard 1960, 18; Hoppe 1995, 25).

Praxeologists also affirm the superiority of reason thesis, agreeing with Leibniz (above) that deductive reasoning is required for necessary inferences with universal application: "Reasoning is always necessarily deductive... The plight of empiricism

\footnotetext{
${ }^{5}$ I reiterate the point that although praxeologists share aspects of Cartesian methodology, they do not do for identical reasons. For example, after Descartes and Leibniz, Kant (1996) distinguished analytic and synthetic a priori knowledge. This important distinction has generated a substantial amount of research and debate, and Praxeology's foundation is a synthetic a priori proposition. I will not discuss this further, but see Smith (1990) and Selgin (1990).

${ }^{6}$ Rothbard essentially restates the cogito when criticising behaviourism: "the existence of consciousness is not only evident to all of us through direct introspection, but is also a fundamental axiom, for the very act of doubting consciousness must itself be performed by a consciousness" (Rothbard 1960, 10).

${ }^{7}$ Hoppe also uses this exact structure to justify his 'axiom of a priori of argumentation', the foundation for his 'argumentation ethics': "humans are capable of argumentation... the validity of the axiom, like that of the action axiom, is indisputable. It is impossible to deny that one can argue, as the very denial would itself be an argument" (Hoppe 1995, 65).
} 
consists precisely in its failure to explain satisfactorily how it is possible to infer from observed facts something concerning facts yet unobserved" (Mises 1962, 21, see also: Selgin 1990, 13; Hoppe 1995, 29). As Mises summarises:

He who wants to attack a praxeological theorem has to trace it back, step by step, until he reaches a point in which, in the chain of reasoning that resulted in the theorem concerned, a logical error can be unmasked. But if this regressive process of deduction ends at the category of action without having discovered a vicious link in the chain of reasoning, the theorem is fully confirmed. (Mises 1962 71-2)

Mises claims praxeology "draws its strength" from its foundational axiom and states: "No economic theorem can be considered sound that is not solidly fastened upon this foundation by an irrefutable chain of reasoning. A statement proclaimed without such a connection is arbitrary and floats in the air" (Mises 1998, 68).

Just as Descartes hoped to secure the new science upon an indubitable foundation, so too do praxeologists speak of the need to "build the theory of catallactics [i.e. exchanges] upon the solid foundation of a general theory of human action, praxeology" as this will "secure it against many fallacious criticisms" and "clarify many problems hitherto not even adequately seen, still less satisfactorily solved" (Mises 1998, 7; see also Hoppe 1995, 26).

\subsection{Reductionism}

Rule V of Descartes' Regulae reads:

The whole method consists entirely in the ordering and arranging of the objects on which we must concentrate our mind's eye if we are to discover some truth. We shall be following this method exactly if we first reduce complicated and obscure propositions step by step to simpler ones, and then, starting with the intuition of the simplest ones of all, try to ascend through the same steps to a knowledge of all the rest. (CSM I, AT X 379)

This is reductionism: approaching a complex problem by first breaking it down - 'reducing it' - to a series of simpler problems, finding solutions to the simpler problems, and combining these simple solutions to solve the complex problem.

For praxeology, actions are atomic. Complex economic phenomena are reducible to the particular actions that compose them: "The study of man, as far as it is not biology, begins and ends with the study of human action" (Mises 1962, 34). Actions are the 'ultimate givens', i.e. phenomena "which cannot - at least in the present state of knowledge - be further analysed" (Mises 1998, 68).

\subsection{Judgement}

Descartes maintained that what we experience in perception is not what is given in raw, sensory 'data'. Perception requires an accompanying intellectual act, i.e. a judgement: 
...if I look out of the window and see men crossing the square, as I just happen to have done, I normally say that I see the men themselves... Yet do I see any more than hats and coats which could conceal automatons? I judge that they are men. And so something which I thought I was seeing with my eyes is in fact grasped solely by the faculty of judgement which is in my mind. (CSM II, AT VII 32)

...even [objects] are not strictly perceived by the senses or the faculty of imagination but by the intellect alone, and... this perception derives not from their being touched or seen but from their being understood. (CSM II, AT VII 34). ${ }^{8}$

Mises agreed with this account, writing that "perception is more than just sensuous apprehension... it is an intellectual act performed by the mind" $(1962,71)$. Mises' account of action is likewise intellectualist: "behaviour begot by judgements of value, aiming at a definite end and guided by ideas concerning the suitability or unsuitability of definite means" (Mises 1962, 34 emphasis mine). Likewise, Hoppe characterises action as "a cognitively guided adjustment of a physical body in physical reality" (Hoppe 1995, 70 emphasis mine). Judgements are also integral to our perception and understanding of others' actions. Just as Descartes held that we do not sense men but rather hats and coats, praxeologists maintain that all we do not see actions but merely bodily movements which we judge to be purposeful behaviour (Hoppe 1995, 22 and 61).

The picture that emerges might be characterised by the following general schema:

\section{World - Stimuli - Sensation - Perception - Will - Motor Output (i.e. Action) - Effect}

Explained in more detail, an object or 'state-of-affairs' in the world (or in the agent's body) serves as a stimuli and, via the senses, is perceived by the agent (which involves an act of judgement). The agent decides a course of action based on the information available to them, i.e. they make a judgement (akin to saying 'I prefer possible state of affairs X to possible state of affairs Y'), and this act of will is then transformed into agency (via the motor system) in order to produce the intended effect.

\subsection{Dualism}

Descartes famously advanced substance dualism. Res extensa, material substance whose essence is spatial extension, is distinguished from res cogitans, mental substance whose essence is thought.

According to the Cartesian view, the material universe can be explained via impact or contact mechanics. Res extensa consists of small, unobservable particles of matter 'corpuscles' - possessing geometric properties such as size and shape. Other properties (e.g. 'heat', 'cold', 'moistness', etc.) require explanation in terms of geometric properties by analysing corpuscles' interaction, i.e. their impacting/contact with one another.

\footnotetext{
${ }^{8}$ In the second meditation, Descartes also gave his famous example of the wax. Descartes points out that although an object may change its qualities - that when the wax melts, it might change its shape, it's smell, it's colour, it's texture - we still judge it to be the same wax, despite that what is given to our senses has changed significantly (CSM II, AT VII 30).
} 
Material things should ultimately be understood in terms of spatial extension, the essence of material substance (see Slowik 2014). ${ }^{9}$

Descartes maintained that the human body is "a machine", claiming "this would not seem strange to those who know how many different automata or moving machines can be made by the industry of man" (CSM I, AT VI 55-6; see also CSM I, AT XI 130). Descartes considered William Harvey's account of the circulation of the blood, given in De Motu Cordis, a paragon of mechanistic explanation (CSM I, AT VI 50), and recommended his readers witness or perform a dissection of an animal so they may understand how the heart moves blood around the body (CSM I, AT VI 47).

If animal behaviour can be explained mechanically, then we may consider animals to be automata. Descartes believed all animal behaviour is - in principle - amenable to such mechanistic explanation, and therefore that animals lack mental faculties: "I cannot share the opinion" writes Descartes, "of... [those] who attribute understanding or thought to animals" (CSM III, AT IV 573-4). However, Descartes identified two facets of human behaviour that demonstrate our rationality. Descartes maintained that reason, absent from animals, is irreducible to extension and, a fortiori, incapable of being reproduced by automata: rationality requires us to postulate a mental substance, res cogitans. Descartes identified two uniquely human types of behaviour that demonstrate our rationality.

First, ordinary human speech exhibits considerable 'creativity': we respond appropriately to everything in our presence across a range of situations, but in a manner not (rigidly) determined by any particular stimulus. Mere emission of language does not require postulating res cognitans - as the Cartesian philosopher Gérard du Cordemoy pointed out, that a word is carved into a rock does not indicate the presence of thought in the rock $(1668,8)$. Automata could certainly be designed to emit "words, and even [utter] words which correspond to bodily actions causing a change in its organs (e.g. if you touch it in one spot it asks what you want of it, if you touch it in another it cries out that you are hurting it, and so on)" (CSM I, AT VI 56-7). But this is a fixed response to a particular stimulus: "it is not conceivable that such a machine should produce different arrangements of words so as to give an appropriately meaningful answer to whatever is said in its presence, as even the dullest of men can do" (CSM I, AT VI 56-7).

Animals, note Descartes, are similarly distinct from humans. They do not display our mastery of arranging words, but this is not because they lack the requisite speech organs - "magpies and parrots can utter words as we do: that is, they cannot show that they are thinking what they are saying" (CSM I, AT VI 57-58). Although animals can be trained to utter words this can only be achieved, contends Descartes, "by making the utterance of this word the expression of one of its passions" (CSM III, AT IV 574). Like automata, animal use of words seem to be fixed responses to particular stimuli, and this is in stark contrast to humans. The explanation, Descartes maintained, is the absence of thought in animals and its presence in humans:

\footnotetext{
${ }^{9}$ N.B. 'Secondary qualities', e.g. colour, tactile sensations, tastes, etc., are therefore to be explained in terms of spatial extension, in these cases via the interaction of the matter which composes the perceived object with the matter that composes our own sensory apparatus and nervous system.
} 
...there has never been known an animal so perfect as to use a sign to make other animals understand something that bore no relation to its passions; and there is no human being so imperfect as not to do so, since even deaf-mutes invent special signs to express their thoughts. This seems to me a very strong argument to prove that the reason why animals do not speak as we do is not that they lack the organs but that they have no thoughts. (CSM III, AT IV 575)

Ordinary, 'creative' language use thereby functions as a means by which we may judge whether a being has a mind: "if I find by all the experiments, I am capable to make, that they use speech as I do, I shall think, I have an infallible reason to believe that they have a soul as I" (Cordemoy 1668, 14). Essentially, Descartes and Cordemoy anticipated the 'Turing test' (Turing 1950; see also Oppy and Dowe 2011).

The second reason Descartes believes res cogitans necessary is that human reason is "a universal instrument which can be used in all kinds of situations" (CSM I, AT VI 57). By contrast, "even though such machines might do some things as well as we do them, or perhaps even better, they would inevitably fail in others, which would reveal that they were not acting through understanding but only from the disposition of their organs... these organs need some particular disposition for each particular action" (CSM I, AT VI 57). This too applies to animals: "I believe that there may be some animals which have a natural cunning capable of deceiving the shrewdest human beings. But I consider that they imitate or surpass us only in those of our actions which are not guided by thought" (CSM III, AT IV 573). Indeed, Descartes considered this observation served "to prove that they act naturally and mechanically, like a clock which tells the time better than our judgement does", and therefore "when the swallows come in spring, they operate like clocks" (CSM III, AT IV 575).

This point is related to what Markie terms the 'indispensability of reason' thesis: "The knowledge we gain in subject area, S, by intuition and deduction... could not have been gained by sense experience" (2015). That is, sensation is insufficient for knowledge. If reason is uniquely human, then there is a sphere of knowledge accessible only to human beings. As Leibniz puts it, our ability to formulate necessary, universal truths "often lets us foresee events without having to experience links between images, as beasts must. Thus what shows the existence of inner sources of necessary truths is also what distinguishes man from beast" (Leibniz 1704, 4).

Cartesian substance dualism has since been rejected. However, as Chomsky (2005) notes, its downfall was due to its defective conception of matter, not mind. Newton's 'occult' attractive force (gravity) challenged the mechanical philosophy by denying matter-matter interaction was restricted to impact/contact mechanics: "Newton eliminated the problem of the 'ghost in the machine' by exorcising the machine; the ghost was unaffected" (Chomsky 2005, 84). Following Newton, Locke acknowledged the possibility that God "joined and fixed to matter... a thinking immaterial substance", but then stated that "God can, if he pleases, superadd to matter a faculty of thinking" and that He could, "if He pleased, give to certain systems of created senseless matter, put together as He sees fit, some degrees of sense, perception, and thought" (Locke 2014, 4.3.6). Absent a new account of matter, then, there is no motivation for either postulating a thinking substance or denying the possibility of 'thinking matter' - "the 
phrase 'material' ('physical', etc.) would simply offer a loose way of referring to what we more or less understand and hope to unify in some way" (Chomsky 2005, 84).

Despite the rejection of substance dualism, Cartesian remains extremely influential (see Hornsby's point, above). Mises explicitly advances it: "the fundamental fact about the universe is that it is divided into two parts, which - employing terms suggested by some philosophers, but without their metaphysical connotation - we may call res extensa, the hard facts about the empirical world, and res cogitans, man's power to think" (Mises 1962, 125). ${ }^{10}$ This Cartesian distinction underpins, in Mises' view, the demarcation between psychology - which studies "the internal events that result or can result in a definite action" and praxeology - whose theme is "action as such" (Mises 1998, 12), where action is defined as "will put into operation" or a meaningful response to particular stimuli (Mises 1998, 11).

Reinstating the Cartesian demarcation of an inner, mental realm was integral to the cognitive revolution of the 1950s and 60s. Initiated by Chomsky's early work, the prevailing behaviourist paradigm (which claimed that the mental, being unobservable, was not amenable to scientific study) was overthrown ${ }^{11}$ and powerful new tools were developed to study "the inner mechanisms that enter into thought and action" (Chomsky 2005, 5). The study of mind involves the methodological exclusion of the external world and our sensory apparatus:

...in the determination of structure from motion, it is immaterial whether the external event is successive arrays of flashes on a tachistoscope that yield the visual experience of a cube rotating in space, or an actual rotating cube, or the stimulation of the retina, or optic nerve, or visual cortex... It is also immaterial whether people might accept the nonveridical cases as 'seeing a cube' (taking 'seeing' to be having an experience, whether 'as if' or veridical); or whether concerns of philosophical theories of intentional attribution are addressed... To take another standard example, on the (rather implausible) assumption that a natural approach to, say, jealousy were feasible, it is hardly likely that it would distinguish between states involving real or imaginary objects. (Chomsky 2005, 23; see also Fodor 1980)

The demarcation of an inner, mental realm, as distinct from the outer world, is the sine qua non of Cartesianism. Mind is not simply equated with brain, though it is assumed that the mind is neurally instantiated - Jackendoff (2003) summarises this general picture by distinguishing, on the one hand, 'functional', mental processes formalised in computational terms from, on the other hand, our neural architecture

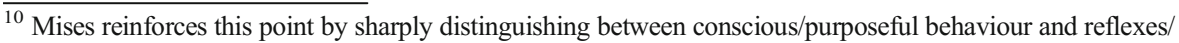
involuntary responses $(1998,11$; see also 1962, 80).

${ }^{11}$ Chomsky's (1959a) devastating review of B. F. Skinner's Verbal Behaviour is considered a foundational text in the modern study of mind. Later Chomsky (1971) also demolished B. F. Skinner's political works: Beyond Freedom and Dignity, where Skinner claimed, first, that behaviourist psychology and its technique of 'operant conditioning' provides an effective means of social control and, second, that we should stop 'fetishising' freedom and deploy this technology to create a more peaceful, prosperous society; Walden II, a fictional story written by Skinner about the society he envisaged being created via operant conditioning.
} 
and activity: Cartesian dualism is firmly entrenched in cognitive psychology. ${ }^{12}$ Descartes' characterisation of ourselves as thinking beings (CSM II, AT VII 28) introduced "a new and unheard of notion of mind (understood in terms of thought) that has exercised his philosophical posterity ever since" (Alanen 2014, 91).

Mises and Rothbard both agree with Descartes that the mind is not amenable to the same kind of explanation as physical reality: our ability to give causal explanations is restricted to those phenomena amenable to mathematical explanation; action must be understood conceptually and explained teleologically. However, Mises and Rothbard justify this Cartesianism differently. For Mises, the inner/outer distinction results from a lack of knowledge:

We do not know how out of the encounter of a human individuality, i.e., a man as he has been formed by all he has inherited and by all he has experienced, and a new experience definite ideas result and determine the individual's conduct...

It is precisely the lack of such knowledge that generates the fundamental difference between the natural sciences and the sciences of human action (Mises 1962, 58)

Rothbard (1960, 12; 1961, 27) advances a stronger claim: it is impossible to capture action mathematically. The physical sciences successfully employ mathematical methods to study the external world because material objects are amenable to measurement. By contrast, "the magnitudes in consciousness are necessarily intensive and therefore not capable of measurement" (Rothbard 1960, 12).

Interestingly, Mises' remarks on animals mirror some of Descartes' conclusions (though not necessarily the latter's reasons). Like Descartes, Mises believes animals lack reason: "We interpret animal behaviour on the assumption that the animal yields to the impulse which prevails at the moment" $(1998,16)$. Descartes' proto-Turing test was intended to demonstrate the stimulus-independence of rational thought. By assuming animal behaviour to be purely impulsive, Mises is emphasising its stimulus-dependence, sharing Descartes' beliefs concerning animal behaviour. Man differs from the animals in this respect: "all the other things, animate or inanimate" conform to "regular patterns" - that is, "man alone seems to enjoy - within definite limits - a modicum of freedom" (Mises 1962, 11). Regarding other animals, Mises says: "We are fully aware of the unbridgeable gulf separating our reason from the reactive processes of the brains and nerves... They [animals] are like prisoners anxious to break out of the doom of eternal darkness and inescapable automatism" (1998, 34 emphasis mine).

\footnotetext{
$\overline{12}$ Both functional and neural levels are distinct from the 'noetic' level, i.e. conscious experience. Hoppe (1995) misunderstands this, claiming that "the truth criterion for the grammarian's explanation... [is] that the speaker would have to be able - in principle - to verify the correctness of the explanation after what was previously known implicitly was made explicit" (Hoppe 1995, 43). This is false. Neither introspection nor reflective cognition provide any means for the speaker to determine which of a proposed set of transformational rules is correct, whether syntactic trees are 'flat' or binary branching, whether derivations proceed by phase or require (multiple) syntax-internal levels of representation, etc. Generative linguistics is mentalistic, i.e. concerned with the speaker-hearer's knowledge ('competence'), but this implies neither that speakers are aware of the rules of their grammar, nor that they can verify them introspectively, nor that any statement they make about their linguistic competence is accurate. As Chomsky puts it: "Any interesting generative grammar will be dealing, for the most part, with mental processes that are far beyond the level of actual or even potential consciousness" (1965, 8 emphasis mine).
} 


\subsection{Methodological individualism}

Summarising the above: Complex economic phenomena should be reduced to the atomic units of praxeological analysis - individual actions. Action consists in substituting a less desirable for a more desirable state-of-affairs, 'cognitively guided' by a judgement of value. Judgements are intellectual acts performed by res cogitans and absent from res extensa - a dualist conception (though not substance dualism). Hence, action must be understood teleologically, either because, as Mises argued, causal explanation is impossible in our current state of knowledge or, as Rothbard maintained, properties of consciousness are not amenable to measurement. ${ }^{13}$ Hence (in our present state of knowledge) we must adopt methodological dualism: Praxeology must proceed, in contrast to the natural sciences, via deduction from the the action axiom which is intuited in reflective cognition.

These 'Cartesian' positions support methodological individualism: judgements of value are necessary for action, judgements are made by res cogitans, only individuals are endowed with mental faculties, therefore only individuals act, therefore complex phenomena reduce to the actions of individuals. As Rothbard summarises:

Only an individual has a mind; only an individual can feel, see, sense, and perceive; only an individual can adopt values or make choices; only an individual can act. This primordial principle of 'methodological individualism'... must underlie praxeology as well as the other sciences of human action. It implies that such collective concepts as groups, nations, and states... are only metaphorical constructs for describing the similar or concerted actions of individuals. (Rothbard 1973, 54)

As Rothbard makes clear, 'social wholes' are of no explanatory value. Mises describes the use of "holistic concepts like nation, race, or church" as a "faulty method" $(1998,1)$. It is 'hypostatisation', i.e. ascription of "substance or real existence to mental constructs or concepts" (Mises 1962, 78). This is not to say holistic entities are fictions $(1998,62)$. Rather, that they are epiphenomena:

...society itself is neither a substance, nor a power, nor an acting being. Only individuals act. Some of the individuals' actions are directed by the intention to cooperate with others. Cooperation of individuals brings about a state of affairs which the concept of society describes. Society does not exist apart from the thoughts and actions of people. It does not have 'interests' and does not aim at anything. The same is valid for all other collectives. (Mises 1962, 78-9)

Praxeology therefore begins with an analysis of individual action, and only later is "cognition of human cooperation is attained... social action is [therefore] treated as a special case of the more universal category of action as such" (Mises 1998, 41). Indeed, Mises contends, it is only possible to understand the formation and dissolution of social wholes via individuals as any given collective "comes into existence by ideas that move individuals to behave as members of a definite group and goes out of existence when

$\overline{13}$ This mention of 'measurement' is interesting: spatial measurement is integral to Descartes' res extensa. 
the persuasive power of ideas subsides" and therefore the "only way to a cognition of collectives is the analysis of the conduct of its members" (Mises 1962, 81). This is particularly the case when individuals are members of different groups, and those groups might have been formed for conflicting purposes:

Those who want to start the study of human action from the collective units encounter an insurmountable obstacle in the fact that any individual at the same time can belong and... really belongs to various collective entities. The problems raised by the multiplicity of coexisting social units and their mutual antagonisms can be solved only through methodological individualism. (Mises 1998, 43)

\section{Information and action}

Mises characterised "social cooperation as emanation of rationally recognised utility" (1951, 418). Hayek (1946) argued that adopting the rationalist conception of individuals makes it difficult to understand spontaneous orders and non-compulsory conventions, stating that Mises' characterisation always made him feel uneasy (1978, xxiii).

In this section, I draw on work in philosophy and the cognitive sciences to outline an alternative, 'Hayekian' approach to each of the Cartesian concepts identified above: dualism is dissolved as they do not faithfully characterise the phenomena in question; nontrivial causal spread, i.e. that behaviour may not be controlled by a well-demarcated system and need not require acts of judgement; emergence, i.e. certain economic phenomena arise from but are irreducible to individuals' actions; patterns may be studied via experiments and models without needing to proceed via intuition and deduction. In place of emphasising action, I will emphasise information. These alternatives allow us to assume a 'system-level' perspective which, I suggest, might opening interesting new avenues of research.

What follows is Hayekian, not Hayek's. It is not Hayek's because it draws conclusions that Hayek did not and incorporates concepts which were not (explicitly) formulated when Hayek was writing many of his works. ${ }^{14}$ (Additionally, Hayek himself is not referenced in the initial subsections. Philosophical positions articulated there will be integral to the 'Hayekian' position articulated subsequently.) It is Hayekian in spirit: it is inspired by Hayek's writings and shares his concern with information, complex systems, and spontaneous order.

\subsection{Dualism dissolved}

Attempts to dispense with Cartesian dualism have often taken the form of reducing or eliminating one half of it, thereby arguing for a monism (i.e. eliminating res cogitans and reducing 'mental' phenomena to res extensa ${ }^{15}$ ). Wittgenstein - in his later work held a different view, believing that it was vain to attempt to solve this problem. Instead, we should dissolve it, recognising that the dualism does not faithfully describe the

\footnotetext{
${ }^{14}$ Hayek scholars claim - correctly, I think - that he anticipated many of these concepts and, in later work, explicitly developed some of them (see Lewis 2012).

${ }^{15}$ Or, in Berkeley's case, reducing all material things to ideas.
} 
phenomena in question. Wittgenstein therefore described his aim as follows: "to teach you to pass from a piece of disguised nonsense to something that is patent nonsense" (2001, §464). Wittgenstein came to believe that philosophy's purpose is to untie knots in our thinking:

Why is philosophy so complicated? It ought, after all, to be completely simple. Philosophy unties knots in our thinking, which we have tangled up in an absurd way; but to do that, it must make movements which are just as complicated as the knots. Although the results of philosophy are simple, its method for arriving there cannot be so. $(1975, \S 2)$

Our thought is knotted because we suppose that minds are principally concerned with judgements and logical reasoning. If we are to unravel this confusion, we must reexamine the phenomena. Merleau-Ponty shared this view, writing: "True philosophy consists in relearning to look at the world" (2006, xxiii). Redescribing phenomena - as later Wittgenstein and the existential phenomenologists (notably Heidegger and Merleau-Ponty) did - not only alleviates our confusions but can provide new concepts to guide research.

The Cartesian assumes that relatively little information is available to the organism from the environment, and consequently that perception must involves intellectual acts (see above). By contrast, Gibson's Ecological Approach to Visual Perception (1979) proposes that significantly more information is available to the organism than Cartesians assume. The environment consists of structures whose surfaces reflect some wavelengths of light and absorb others. At any given point of observation light converges from all directions but, due to the shapes and surfaces this light has been reflected off, the converging light carries patterns. This patterned convergence of light is the ambient optic array (Gibson 1979, 51). Rowlands (1995) draws two lessons from Gibson: first, the amount of information processing that the organism must perform internally is inversely proportional to amount of information built into the structure of the input; second, we cannot understand what information processing the organism must engage in without understanding the structure of the input.

Rowland also emphasises another aspect of Gibson's thought: dynamics. Movement transforms the optic array, and these transformations are themselves potent sources of information about the organism's orientation and its environment's structure. Organisms can therefore engage in information processing by manipulating aspects of the environment; information processing is not restricted to internal, mental stuff but is accomplished via action (Rowlands 1995).

Manipulation of the environment presupposes our embodiment, perhaps the central theme of Merleau-Ponty's Phenomenology of Perception (2006). Drawing on Kurt Goldstein's studies of brain damaged patients, Merleau-Ponty notes that our perceptual experience is shaped by the form and nature of our bodies - we perceive cups as things to grasp and drink from because the structure of our hand enables a certain type of grip and our need for fluid intake motivates us to drink. Perception is structured by practical possibilities: "Consciousness" writes Merleau-Ponty "is in the first place not a matter of 'I think that' but of 'I can'” (Merleau-Ponty 2006, 159). In Gibson's terminology, we perceive and understand things in terms of their affordances, that is, our potential 
engagements with them. A corollary is that creatures with different bodies will perceive objects differently - we will perceive a power cable as something to be avoided whereas a bird might view it as something to perch on. Further, the structure of objects matters: only objects with appropriate shape can be perceived as something to grasp or sit on, and the organism perceives this via structured inputs (visually, through the ambient optic array).

Hence perception and action involve not just our neural architecture but also the objects of our environment and our bodies' morphology. No central controller (whether res cogitans or the brain) has priority: behaviour emerges from the interaction of brain, body, and world. In technical terminology, they are coupled, i.e. necessarily bound to each other and continuously influencing one another. Such conclusions were anticipated by Heidegger. In place of the 'spectatorial' Cartesian conception of an inner self or ego opposed to an outer world, Heidegger spoke of 'Dasein', or 'being there', to denote, first, that we are always bound up with or embedded in our environment and situation and, second, to emphasise that we are primordially actors not reasoners ('being' is a verb). Once we adopt this alternative perspective, problems pertaining to the relation between self and world are dissolved. Self and world are inextricably interwoven:

The 'scandal of philosophy' is not that this proof [of the existence of the external world] has yet to be given, but that such proofs are expected and attempted again and again... It is not that the proofs are inadequate, but that the kind of being of the entity which does the proving and makes requests for proofs has not been made definite enough... If Dasein is understood correctly, it defies such proofs, because, in its being, it already is what subsequent proofs deem necessary to demonstrate for it. (Heidegger 2006, H205)

Symbolic computation tends to be prefered by contemporary Cartesians: an algorithm can be viewed as an internal mental process; symbols as mental entities, i.e. 'ideas', manipulated by the algorithms and often generated by our sensory systems and 'standing for' aspects of the world. Those who reject the Cartesian res cogitans/res extensa dualism will therefore tend to eschew symbolic computation in favour of dynamical systems theory (DST), modelling cognition geometrically. The 'dynamical hypothesis', that cognitive agents are dynamical systems (Van Gelder 1998, 615), implies that behaviours are trajectories through the system's state space and that cognitive processes should be reconceived as state space evolution within complex, dynamical systems $(1995,346){ }^{16}$

\footnotetext{
${ }^{16}$ Van Gelder (1995, 359-60) notes how expected utility and rational expectations theory encounter at least three problems relating to the temporal aspects of decision making: first, they neglect the reasons for the motivations behind the utility a given object/outcome has at a given time; second, utility and preferences are conceived statically resulting in problems of dynamic inconsistency and instability; third, they offer no account of the agent's deliberation process. These problems do not arise for praxeology because they are methodologically excluded (they concern psychology, not praxeology). As should become clear during the rest of this paper, it is highly likely that these problems will become relevant on a 'system level' perspective.
} 
World and body are not sources of raw data that must be taken into account by acting man (Mises 1998, 11). Instead cognition is the complex interaction of brain, body, and world. As Van Gelder summarises:

...the cognitive system is not just the encapsulated brain; rather, since the nervous system, body, and environment are all constantly changing and simultaneously influencing each other, the true cognitive system is a single, unified system embracing all three. The cognitive system does not interact with the body and the external world by means of occasional static symbolic inputs and outputs; rather, interaction between the inner and outer is best thought of as a matter of coupling, such that both sets of processes continually influencing each other's direction of change. (1995, 373 emphasis mine)

Therefore we may ask whether economic agents are coupled to structures and institutions, and how these structures and institutions themselves engage in information processing. These questions are recast in light of other considerations in subsequent sections.

\subsection{Nontrivial causal spread}

Praxeologists contend: "Each action presupposes an ingredient that is entirely distinct from knowledge and information, namely, a judgement upon the conditions prevailing in the future" (Hülsmann 1997, 36). Without judgements there are no actions, only the "instinctive urges" and "conditioned reflexes" common to all animals (Mises 1962, 49). Judgements are produced by the understanding, i.e. our mental faculties, as opposed to being mere bodily movements. However, as noted in the previous section, philosophers such as Wittgenstein, Heidegger, and Merleau-Ponty, sought to dissolve this res cogitans/res extensa dualism by redescribing the phenomena, emphasising the embodied, situated, and practical nature of experience. Such themes are present in Gibson's ecological psychology - especially within the concept of 'affordances' - and find a natural ally in geometrical models of cognition. Rather than conceiving of minds as "disembodied logical reasoning devices" devoted to intellectual acts, we might consider minds inherently action-oriented: "Minds make motions, and they must make them fast - before the predator catches you, or before your prey gets away from you" (Clark 1997, 1).

Rowland highlighted the following important points from such actionoriented accounts: first, the more information contained in the structure of the input, the less 'load' is placed on the organism; second, understanding the input's structure is essential for understanding the information processing task confronting the organism; third, organisms may process information via acting within and manipulating their environment. In this section I will draw on robotics and behavioural economics to further explore these themes and present an alternative to Misesian conception of action as "behaviour begot by [internal] judgements of value" (Mises 1962, 34). Central to this section is the concept of nontrivial causal spread, which "occurs whenever something we might have expected to be achieved by a well-demarcated system turns out to 
involve the exploitation of more far flung factors and forces" (Clark 2011). ${ }^{17}$ Conceiving of cognition as nontrivially spread is to assume that nature 'designs' creatures to take advantage of their environment's structure, that objects and institutions actively contribute to cognition by processing information, and that creatures may modify or create new objects and institutions in order achieve what they otherwise could not (extending Rowland's first, second, and third points respectively). In this section I will focus on the contribution of environmental structure, discussing the role of objects and institutions in the next section. I will first introduce several examples from robotics to demonstrate instances of 'distributed control', where mechanisms realising behaviour are nontrivially spread, then draw on behavioural economics and constructivist accounts of preference formation to suggest that at least some actions may occur without accompanying judgements of value.

Faced with a complicated environment, an engineer might assume that robots require elaborate programming to navigate successfully. But as Webb, who built a robot designed to mimic phonotaxis in female crickets (1996), puts it:

Counteracting the complex effects of the environment... seems to require control algorithms of a matching sophistication. But does it really? An alternative, increasingly popular approach in robotics is to design the robot so that its interaction with the environment is exploited rather than resisted. (Webb 1996, 63)

Action within a complex environment could be less a matter of sophisticated mental structure and more attunement to information already given by the environment. Male crickets emit a species-specific signal ${ }^{18}$ and females are able to navigate through complex environments to its source, differentiating it from background noise. Rather than design recognition and navigation systems as complex as the environment, Webb's robot mimicked cricket morphology.

\footnotetext{
${ }^{17}$ Hodgson (2007) identifies two variants of methodological individualism:
}

(a) Social phenomena should be explained entirely in terms of individuals alone

(b) Social phenomena should be entirely explained in terms of individuals plus relations between individuals (i.e. in terms of individuals and social structures)

Hodgson notes that (a) has never been achieved in practise, as researchers ostensibly using methodological individualism have always presupposed that individuals are in relations with one another (and their external environment). However, Hodgson then notes that in the case of (b) the term 'methodological individualism' is unwarranted; labels such as 'methodological institutionalism' or methodological structuralism' would be equally legitimate. Perhaps a more useful distinction is between trivial and nontrivial causal spread. That individuals have always been situated within social structures and ecological contexts is undoubtedly true, but for a Misesian this fact is, qua praxeology, trivial. Social/institutional/environmental structures are sources of data for the economic agent. Praxeologists consider action to be produced by a well-demarcated system - acting man who enters into social relations with others by having certain beliefs about these relationships (i.e. that someone is an authority figure, and therefore should be obeyed). By contrast, the 'Hayekian' position I am articulating considers the 'situatedness' of the agent to be nontrivial, i.e. that the economic agent is not well-demarcated and that institutional and environmental structures are (in part) constitutive of cognition.

${ }^{18}$ Both frequency and temporal pattern are species-specific. 
Female crickets have two ears, one on each of their front legs. These are connected to one another via a tracheal tube. There are two ways sound can reach a given ear: externally, directly from the sound source; internally, via the trachea. Hence, on the side of the sound source, the externally arriving sound travels less distance than sound arriving internally. Each ear is connected to a neuron which fires when it reaches a certain activation threshold. Because the ear on the side of the sound source has a higher vibration amplitude, that neuron will fire first.

Webb inferred that with each burst of sound, the cricket moves to the side of the neuron that fires first: females respond only to the beginning of the male signal. Here the frequency and temporal structure of the male's signal becomes important. If the gaps between syllables are too long, the female receives insufficient information. Likewise if the gaps are too short: The female's neurons have a recovery period where they return gradually to their non-activated rest state. During this time the neuron is closer to its firing threshold than if it were at rest. If the gaps between the male's syllables are too short the female's neurons will not have time to return to their rest state, and therefore with each new signal from the male it would be unclear which of the female's neurons had fired first. Phonotaxis can be accomplished by the cricket continuously turning to the side on which firing begins (Webb 1996, 65). By imitating this structure, Webb's robot proved capable of flexible behaviour in a dynamic environment.

Control is therefore nontrivially spread between the cricket's neurons, its morphology, and the external sound source. The cricket/robot's morphology 'attunes' it to the structure of the male's signal, and this removes the need to distinguish it from background noise: the cricket's trachea best transmits the sounds of the male's song, and therefore the cricket "did not need to select the right song actively - [the system] simply did not work for the wrong song" (Webb 1996, 66). Therefore an aspect of the environment (the temporal structure of the male's song) is integral to the system. Finally, the cricket's neurons require correct placement to adequately distinguish wavelengths of signals from the external and internal sources. Brain, body, and world all contribute to successful navigation, together forming a coupled dynamical system (Van Gelder's proposal, above); the system as a whole accounts for behaviour, and the creature/robot is designed to take advantage of given structures.

Framing Webb's robot in terms of Rowland's points (above): the amount of information processing required is minimised by exploiting the signal's structure; understanding the structured information given by the environment better equips us to understand the nature of the computational task the organism faces; dynamics is crucial, i.e. navigation through the environment was not determined statically, but unfolded continuously as the organism/robot moved and in response to the signal's fluctuations (N.B. movement causes the signal's amplitude to change; movement is effecting information processing).

If this model is correct then the cricket's 'purposeful behaviour' involves no act of judgement. A praxeologist may counter that all this reveals is that the cricket's behaviour is not action proper, and may safely be included within Mises' own description of animal behaviour as devoid of intellect. But there is an interesting question that should be asked: to what extent can this model 'scale up' to higher cognitive functions? 
The idea of using the environment's structure is famously associated with Rodney Brooks who captured our propensity to attribute more internal structure than is necessary with the phrase: "Intelligence is in the eye of the observer" (1991, 16; see also 1985, 3). Brooks built robots consisting of layers of behaviour producing machines, where each machine could be conceived as something like Webb's cricket robot (a functional, behaviour-producing module). Higher machines may inhibit data flow within/the output of the lower machines - higher components are therefore said to subsume the lower ones (e.g. one machine might continuously drive the robot forward, whilst a higher machine inhibits this forward motion if it detects an object in the robot's path). This overall design is referred to as the 'subsumption architecture' (Brooks 1985, 7).

Robots built according to this architecture have no central locus of control, their perceptual, central, and actuation systems are intertwined (just as Webb's cricket robot was, above), and although some layers might presuppose the existence of lower layers, each layer can be considered 'behaviour-producing' (1991, 17-8; see also 1990). In a "simplistic and crude" analogy to evolution, the performance of the system can be enhanced by adding additional layers of behaviour-specific machines. It is not just these additional components which enable new forms of behaviour to arise, but the interaction of this "mess of many mechanisms working in various ways" $(1992,14)$. The system's overall intelligence arises from the coupling of the robot's components to aspects the world $(1991,16)$.

Despite the subsumption architecture's efficiency, it is unlikely that such layered machines are capable of 'scaling up' to imitate the full range of human behaviour. First, our species' linguistics and mathematical abilities require a more computationally powerful system (see Chomsky 1956, 114-6; see also 1959b and 1965), and this might necessitate intellectual acts to account for at least some economic phenomena calculation, for example, which relies on arithmetical ability (see Herbener 1996). The second reason for scepticism is that, in the above explanation, the robots are characterised as being 'reactive', doing whatever behaviour arises from the interaction of the their systems and their environment. However, certain behaviours, such as knowing how to navigate from A to B seem to indicate the need for mental structure. The obvious strategy is to have robots generate an internal map with locations and regions marked, then engage in a 'judgement', i.e. a 'decision' to move along a given route to one location.

Mataric (1990) adopted a different strategy, based on the neurobiology of rats. ${ }^{19}$ The robot does generate an internal map with landmarks. However, these landmarks implement behaviours and are connected to other landmarks by 'motion directives' such that at any given landmark the robot 'knows' how to reach other landmarks. Given a 'goal' at one landmark, a pattern of spreading activation occurs where the goal activates nearby landmarks and this activation pattern propagates through the map such that the optimal route to the goal is calculated based on the direction from which activation arrives at each landmark:

Each landmark in the map stores an estimate of its physical length. As the activation wave is propagated through the network, it accumulates the length values of the landmarks it passes. Consequently, at each landmark, the shortest

${ }_{19}$ Mataric's robot uses the subsumption architecture $(1990,171)$. 
path toward the goal corresponds to the direction with the smallest accumulated length. The robot takes the optimal direction locally, at each landmark, which produces the globally shortest path to the goal. (Mataric 1990, 172)

Because propagation through the network of landmarks controls navigation, the need for 'judgement' is obviated: "our approach does not use a separate, centralised reasoning engine outside the network. All spatial reasoning necessary for building and using the map is in the map itself" (1990, 173 emphasis mine).

These examples from robotics suggest that certain sophisticated behaviours may be achievable without accompanying intellectual acts, and perhaps without an internal, centralised locus of control. In the remainder of this section I will draw on the constructivist account of preference formation to suggest that certain consumer behaviours may also be possible without accompanying judgements of value, with control nontrivially spread to take advantage of environmental structure.

Whereas mainstream expected utility theory holds that individuals have pre-existing preferences, constructivist accounts hold that "preferences are often constructed - not merely revealed - in the elicitation process" (Tversky and Simonson 1993, 1187). Preferences are conceived as context-dependent. ${ }^{20}$ The asymmetric dominance effect provides a clear example of the constructivist perspective (see Huber et al. 1982): In a choice between three goods, one good $x$ is asymmetrically dominated if it is similar but inferior to one of the alternatives $y$ but dissimilar to the other $z$. In such cases, the asymmetrically dominated good $x$ is (almost) never chosen, whereas good $y$, similar and superior to $x$, tends to be chosen over good $z$ significantly more than would be the case in the absence of $x$. For this reason the asymmetrically dominated option is called the 'decoy': it is almost never chosen, but strongly influences selection of the similar superior good. The importance of this result for marketers is obvious:

Managerially, [asymmetric dominance] leads to the counterintuitive conclusion that there are times when profitability of a product line can be increased by adding a dominated alternative that virtually no one ever chooses. The effect of the dominated alternative is to draw attention to a more profitable item rather than to generate direct sales. (Huber et al. 1982, 90)

A particularly interesting investigation is that of Ariely and Wallsten (1995), who aim to develop a theory to explain the asymmetric dominance effect and engage in a series of experiments to test their theory. Their 'item preference experiment' reaffirmed the asymmetric dominance effect, but two other experiments - the 'dimensionweighting' and 'value-setting' experiments - investigated what properties, i.e. 'dimensions', of goods we take to be the most important, i.e. the most heavily 'weighted', as well as why these dimensions receive the weightings they do. Ariely and Wallsten provide evidence both that the more heavily weighted dimension is the one that distinguishes the decoy from the similar superior good, i.e. "when the preference

\footnotetext{
${ }^{20}$ There is evidence that preferences stabilise over time, with preferences formed in one context serving as reference points which can be adapted in light of subsequent experience: "Consumers do not go into every situation with a tabula rasa, or blank slate. In fact, it would be maladaptive for consumers to ignore their previous experiences and go through the extensive effort of constructing their preferences for each and every decision they make" (Hoeffler and Ariely 1999, 115).
} 
between the similar items... [is] due to that dimension" $(1995,228)$, that this weighting is a function of the particular context $(1995,231)$, and that the weighting of a dimensions "are essential in the construction of the value of the item itself" $(1995,230)$.

Asymmetric dominance is one of a plethora of phenomena identified by the constructivists demonstrating values to be context-dependent. Consequently, mainstream expected utility theory is insufficient to account for consumer choices: asymmetric dominance contradicts one of von Neumann and Morgenstern's axioms, the 'independence of irrelevant alternatives' (Ariely and Wallsten 1995, 223). As Simonson and Tversky put it:

The prevalence of context effects presents a challenge to marketing researchers and more generally to decision theorists. The systematic failure of value maximisation undermines the standard theory of consumer choice and calls for an analysis that explains the effect of context on choice. $(1992,293)$

Importantly, the constructivist position takes phenomena such as asymmetric dominance not only to imply that there is no complete and consistent list of preferences held in 'master memory', but also that preferences need not be generated by an algorithm such as 'expected value calculation' (Payne et al. 1992, 89).

Constructivism does not undermine praxeology: how values form is a concern for psychologists; praxeologists need only assume that acting man values certain means and ends in order to engage in a priori analysis. Further, behavioural economics and praxeology may be complementary for 'applied' studies: the former can enable us to explain or predict particular, individual acts of choice; the latter can be employed to help us explain or predict the logical consequences of such acts. ${ }^{21}$ For praxeologists, then, that values are context-dependent is irrelevant to the point that actions require judgements over this set of values.

However, we might consider an alternative interpretation based on the studies of robotics (cited above). Just as successful spatial navigation may be achieved without an independent decision-making engine, consumer behaviour could conceivably occur without a judgement of value. Just as the landmarks within Mataric's robot contain 'motion directives', we might adopt a perspective based on DST and conceive of values as being attractors in our cognitive 'state space', value-formation as being state space evolution, and action as being the trajectory determined by the attractors (values). From this vantage point, what guides action are the values themselves, not an independent judgement.

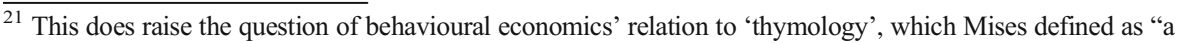
branch of history" which "deals with the mental activities of men that determine their actions. It deals with the mental processes that result in a definite kind of behaviour, with the reactions of the mind to the conditions of the individual's environment" (Mises 1962,47-8). This quote might indicate that behavioural economics could be considered a subdiscipline of thymology, however this is complicated by Mises' remark that "experimental psychology has nothing to say and never did say anything about the problems that people have in mind when they refer to psychology in regard to the actions of their fellow men" (ibid., 47). It is worth noting that Mises wrote those words when the cognitive revolution was in its infancy, and may have been thinking of experimental psychology in terms of the perceptual studies of gestalt psychologists or the mechanistic worldview of the behaviourists. Contemporary praxeologists could perhaps conceive of behavioural economics as the naturalistic study of the mental apparatus engaging in judgements of value, and to use phenomena such as asymmetric dominance in thymological research. I do not pursue this question further here.
} 
Whereas content-dependence is trivial for praxeology, it is nontrivial for this alternative interpretation: Preference formation takes advantage of information given in environmental structure (i.e. comparable differences in goods' dimensions) and these preferences themselves guide action. Although praxeology methodologically excludes phenomena such as asymmetric dominance by declaring all transactions instances of individuals' demonstrated preference, a non-Cartesian interpretation may undermine this exclusion as it might be taken to support the view that

the actual local operations that realise certain forms of human cognising include inextricable tangles of feedback, feed-forward, and feed-around loops: loops that promiscuously criss-cross the boundaries of brain, body, and world... Cognition leaks out into body and world. (Clark 2011, xxviii)

If this alternative interpretation has merit, it is possible to have purposeful behaviour that is not merely 'reflex'. Because such behaviour without judgement would systematically contribute to economic phenomena it seems illegitimate to exclude them from economic science.

\subsection{Emergence}

The previous sections drew on robotics to demonstrate that behaviour in a complex environment need not require equally complex internal structure. Instead the organism might 'couple' with aspects of its environment. Cognition, on this account, resists reduction to the mental/neural processes, and instead is reconceived as the dynamics of an emergent system encompassing brain, body, and world.

Emergent phenomena arise from more fundamental entities, but are irreducible to those entities and, once in existence, exert influence - 'downward causation' - on them (see O'Connor and Wong 2015). Hayek's example of a path illustrates how the actions of individuals produces a structure which, first, those individuals did not intend to bring about and, second, influences those individuals' subsequent actions:

At first everyone will seek for himself what seems to him the best path. But the fact that such a path has been used once is likely to make it easier to traverse and therefore more likely to be used again; and thus gradually more and more clearly defined tracks arise and come to be used to the exclusion of other possible ways. Human movements through the region come to conform to a definite pattern which, although the result of deliberate decisions of many people, has not been consciously designed by anyone. (Hayek 2010, 104)

Such a statement is at odds with the praxeologist's reduction of complex social and economic phenomena to individuals and actions. Emergent social structures exert downward causation; they are not epiphenomena. Consequently, if there exist emergent economic institutions then explanation might be irreducible to individuals and actions, and must instead incorporate these institutions as basic elements.

In this section I introduce the notion of 'cognitive technology', presenting some evidence that our symbolic behaviours should be understood in these terms. I then turn to Hayek's contention that the price mechanism is a means for communicating 
information, interpreting money as cognitive technology and prices as emergent phenomena. Finally, I clarify the Hayekian position by addressing some objections to the 'prices as information' thesis. These objections may be sidestepped if prices are emergent.

In the previous section I acknowledged that certain human abilities - notably language and mathematics - seem to require more a computationally powerful system. Due to the need for arithmetical abilities, economic calculation also seems to fall within this category. Although 'symbolic' behaviour appears to require more sophisticated mental structure, this need not necessitate reinstating Cartesianism - it is possible that only a minimal change in our mental/neural architecture was necessary: a 'spark that lit the intellectual forest fire' (Clark 2001, 151). A small change could allow us to develop 'tools for thinking', i.e. cognitive technologies, augmenting basic mental abilities and allowing us to think thoughts that otherwise we could not. Development of 'first generation' cognitive technology (e.g. words) could grant us the ability to build a second generation (e.g. symbols), which in turn could enable the development of third generation technology (e.g. alphabet), and so on. Hence, an initial alteration could ignite an iterated process of bootstrapping where increasingly sophisticated artefacts are produced allowing increasingly sophisticated thoughts. If true, the Cartesian mistake is confusing the cognitive capacities of the technologically augmented agent with the profile of the biologically basic brain (Clark 1998, 14). To see how this is relevant, I will consider two sources of evidence: chimpanzees and capuchin monkeys trained to use symbols; the Pirahã, a tribe whose language has interesting properties and importantly for our purposes - has no numerals.

Both chimpanzees and capuchins have had their decision-making capacities tested with the reverse-reward contingency task: subjects are given the choice between a large and a small plate of food, and are given the one which they did not select (i.e. if they choose the large plate they receive the small one, and vice versa). Chimpanzees were initially unable to obtain the larger plate by choosing the smaller until they were trained on arabic numerals, which allowed them to acquire the larger plate (see Boysen et al. 1996). Capuchins, trained to use tokens as a kind of 'currency', were able to significantly improve their performance on this task: "tokens allowed capuchins to achieve psychological distancing from the incentive features of food, leading them to avoid impulsive choices in favour of more advantageous alternatives" (Adessi and Rossi 2011, 853; see also Anderson et al. 2008). Such examples are suggestive: our systems of symbols, once internalised, could become 'cognitive building blocks', i.e. objects that can be targeted by our biologically basic cognitive abilities (Clark 2001, 144), thereby transforming the problem space confronting our 'naked' brains and allowing us to solve problems otherwise beyond us.

Turning to the Pirahã, an indigenous Brazilian tribe: the Pirahã language has (amongst other interesting properties) no numerals. Rather, Everett (2005) identifies the following words: hói, a small amount; hoí, a larger amount; baagiso, meaning many or 'to cause to come together'. Pirahã have difficulty with certain matching tasks involving memory (e.g. having previously seen an array of $x$ objects, reproduce that array of exactly $x$ objects). This suggests that number words function as cognitive technologies allowing their users to recall and compare information about cardinalities across space and time (Frank et al. 2008b). Further, English speakers have been shown to perform similarly when given a verbal task to complete whilst they are attempting the matching task (Frank et al. 2008a). 
On this reading, the lack of cardinal numbers would impair the ability to use prices (see Herbener 1996 for discussion). In this respect, it is interesting to read Everett's description of the Pirahã's trade with Brazilians:

Riverboats come regularly to the Pirahã villages during the Brazil nut season. This contact has probably been going on for more than 200 years. Pirahã men collect Brazil nuts and store them around their village for trade... They will point at goods on the boat until the owner says that they have been paid in full. They will remember the items they received (but not exact quantities) and tell me and other Pirahã what transpired, looking for confirmation that they got a good deal. There is little connection, however, between the amount they bring to trade and the amount they ask for. (Everett 2005, 626)

Prices, then, do not seem to emerge: Arguably, the Pirahã have no cognitive technology enabling them to determine a transaction's relative worth.

If true, symbols are not merely 'arbitrary' expressions of internal mental states/ processes (as they are for Cartesians), but technology by which we transform the problem space confronting us and augment our thought. This dovetails nicely with Hayek's writings on spontaneous order:

If it is true that the spontaneous interplay of social forces sometimes solves problems no individual mind could consciously solve, or perhaps even perceive, and if they thereby create an ordered structure which increases the power of individuals without having been designed by any one of them, they are superior to conscious action. (Hayek 2010, 149 emphasis mine)

Hayek recognised the importance of symbols in this process which - as in the following passage - could be interpreted as transforming the problem space:

Though our civilisation is the result of a culmination of individual knowledge, it is not by the explicit or conscious combination of all this knowledge in any individual brain, but by its embodiment in symbols which we use without understanding them, in habits and institutions, tools and concepts, that man in society is constantly able to profit from a body of knowledge neither he nor any other man completely possesses. (Hayek 2010, 146-7 emphasis mine)

Further, Hayek implies these symbols - internalised as concepts and ideas - are emergent, arising from and developing within individual minds, but existing as part of the emergent social order perpetuating itself through individuals:

While concepts or ideas can... exist only in individual minds, and while, in particular, it is only in individual minds that different ideas can act upon another, it is not the whole of the individual minds in all their complexity, but the individual concepts... which form the true elements of the social structure. If the social structure can remain the same although different individuals succeed each other at particular points, this is not because the individuals which succeed each other are completely identical, but because they succeed each other in 
particular relations, in particular attitudes they take towards other people and as the objects of particular views held by other people about them. The individuals are merely the foci in the network of relationships and it is the various attitudes of the individuals towards each other (or their similar or different attitudes towards physical objects) which form the recurrent, recognisable and familiar elements of the structure. (Hayek 2010, 97)

As I argue elsewhere (Malt 2013), money and prices are strong candidates for a cognitive technology. Hayek claimed that "We must look at the price system as... a mechanism for communicating information if we want to understand its real function" $(1945,86)$. Money should be conceived as a symbol characterised by what Clark terms 'dynamical computational complementarity' $(2011,27)$. Money, as a symbol, is a vehicle bearing informational content; as vehicles, monetary units may be manipulated, thereby enabling economic calculation (computation). However, the symbol's content emerges from the system's dynamics. Revisiting Rowland's points (above), prices serve to reduce the information processing required in calculation, and understanding the nature of economic calculation requires understanding how prices encapsulate information.

These points may be made clearer by examining two criticisms of the Hayekian position: Hülsmann's $(1997,26-8)$ argument that social coordination enables prices, not vice versa; Kinsella's (1999, 52-3) claim that viewing prices as conveying informational content requires there to be some information to be encoded, a scheme to encode it, someone to consciously perform this task, and a procedure and person to decrypt it. ${ }^{22}$

Hülsmann contends that all knowledge informing any particular action must have been acquired prior to that action. Therefore a given price "could not have communicated the knowledge that brought it about" $(1997,26)$. Because the actions of buyer and seller must have been coordinated for the price to be established, Hülsmann concludes coordination gives rise to prices, not vice versa $(1997,28)$. Two points should be made in response.

First, Hülsmann seems to consider prices epiphenomenal, i.e. caused by action but not vice versa (though they may be taken into account by acting man's judgements). However, Hayek's talk of prices inducing action hints at a non-Cartesian perspective where, like certain other aspects of the world, prices are parts of a complex system, affording certain actions. As a result, it appears plausible to consider prices an integral part of a feedback loop (see the discussion on stigmergy, below).

Second, prices are intersubjective phenomena: Robinson Crusoe will endure opportunity costs but will not encounter exchange ratios unless he transacts with Man Friday. Further - praxeologists would presumably agree with this - it is doubtful that ratios can be predicted in advance of actual transactions (N.B. 'predicted' understood in a

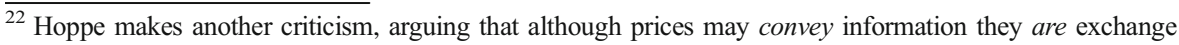
ratios, and therefore cannot be information:

...it is harmless to speak of prices as conveying information. They inform about past exchange ratios. But it is a non-sequitur to conclude that socialism's central problem is a lack of knowledge. This would only follow if prices actually were information. However, this is not the case. Prices convey knowledge, but they are the exchange ratios of various goods, which result from the voluntary interactions of distinct individuals... (1996, 145)
}

This is a logical fallacy (affirming a disjunct). 
technical sense, and ignoring such practicalities as 'educated guesses'). To characterise prices as emergent is to say the information does not exist prior the actual transaction. This leads to Kinsella's criticism.

Kinsella asks "what information, exactly, is supposed to be conveyed by prices?" (1999, 53) Presupposed by this question is that there exists information to convey prior to the price being formed and which may be accessed following a transaction:

...concepts such as encoding, encryption, and the like imply an encoder - a person who actively and consciously encodes information in some communication medium, in accordance with some encoding scheme (i.e., the code). Yet there is clearly no encoding scheme and no way to decode the information. $(1999,52)$

According to the emergentist reading, Kinsella is correct: there is no encoding scheme, no information to be encoded, and no one who is tasked with the encoding or decryption. However, emergence implies dependent novelty. Murray Gell-Mann summed up this feature of emergent phenomena as follows: "You don't need something more to get something more." Applied to money and information: we don't need something more (a new type of physical token and/or an explicit encoding scheme) to get something more (new information). Rather, information emerges from agents' interaction. Kinsella's question may therefore be given an exact answer, at once extremely simple and extremely complex: prices convey themselves.

\subsection{Patterns}

Previous sections presented an alternative to the Cartesian perspective: instead of mind being conceived as an inner realm determining and interpreting action, cognition can be construed as a system encompassing brain, body, and world; a considerable amount of our actions might result from the dynamics of this system, rather than requiring accompanying judgements; those actions requiring judgments (e.g. calculation) might also require a degree of coupling with the environment, being characterised by 'dynamical-computational complementarity'. An alternative therefore exists to the individualism of Cartesian rationalism, namely a view of the individual as, in Hayek's words, "foci in a network of relationships" (2010, 97). If true, complex economic phenomena may be reconceived as dynamic and emergent patterns of interaction, arising from individuals' actions but irreducible to them: Certain economic institutions and processes might influence the behaviour of individuals. Hence, we may perform a gestalt switch and understand some economic phenomena at the system-level, identifying patterns of economic activity. Adopting Hayek's terminology, we engage in pattern prediction. ${ }^{23}$ In this section, I will use the example of crowd dynamics to demonstrate how possible patterns may be identified.

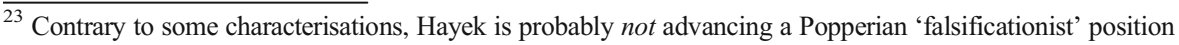
(see Caldwell 1992 for discussion).
} 
Crowds are an example raised by Mises to justify the reduction of collective entities to individuals' belief and actions, i.e. to justify methodological individualism:

It is illusory to believe that it is possible to visualise collective wholes. They are never visible; their cognition is always the outcome of the understanding of the meaning which acting men attribute to their acts. We can see a crowd, i.e. a multitude of people. Whether this crowd is a mere gathering or a mass (in the sense in which this term is used in contemporary psychology) or an organised body or any other kind of social entity is a question that can only be answered by understanding the meaning which they themselves attach to their presence. And this meaning is only the meaning of individuals. Not our senses, but understanding, a mental process, makes us recognise social entities. $(1998,43)$

This interpretation displays the Cartesian features identified above. First, the meaning of the crowd is determined by individuals' inner "mental process[es]", not the physical properties of the agents and/or crowd (dualism). Second, it is the understanding which enables agents to perceive and participate in social entities, not the senses, i.e. judgements of "the meaning which they [acting men] themselves attach to their presence". Hence, third, the collective entity must be understood via reduction to individuals' judgements. Fourth, the behaviour of the collective can therefore be deduced given sufficient information concerning the individuals composing it.

By contrast, an alternative view of crowds takes the individuals as being coupled to one another. Building models in which the behaviour of a given agent depends on the behaviour of other agents is revealing: "Unanticipated forms of collective behaviour emerge that are not obvious from the properties of the individuals themselves" (Strogatz 2003, 263).

Granovetter (1978), for example, developed models of riots. He showed that two crowds can be near-identical in their propensity to riot, and yet very different outcomes may occur. Granovetter assumed that every member of the crowd had a 'threshold', defined as that percentage of the whole crowd that needed to be rioting before that particular member joined in $(1978,1422)$. In a crowd of 100 people, someone with threshold level of 0 will begin rioting without needing anyone else to, and cause anyone with a threshold level of 1 to follow suit. If there is an individual with a threshold of 1 , that person will then start to riot, causing anyone with a threshold level of 2 to begin rioting, etc. If we assume that the crowd of 100 is composed of one person with a threshold of 0 , one person with a threshold of 1 , one with a threshold of 2 , and so on until the final person with a threshold of 99, then when the person with threshold 0 begins it will cause, one by one, the entire crowd to follow suit. However, if the person with threshold one is replaced by another person with threshold 2 (such that there are now two people with threshold 2, and none with threshold 1) then when the initial rioter (threshold 0) begins, no one else will follow suit. Despite the two crowds being extremely close to one another overall, Granovetter notes that newspapers may report one incident as "A crowd of radicals engaged in riotous behaviour" and the second as "A demented troublemaker broke a window while a crowd of solid citizens looked on" (Granovetter 1978, 1425). 
Granovetter's work is suggestive: “threshold models take the 'strangeness' often associated with the collective behaviour out of the heads of actors and put it into the dynamics of situations" $(1978,1442)$. But there is nothing particularly challenging to methodological individualism - arguably it is a confirmation of Mises point that we may only understand a collective via individuals (namely, their particular thresholds). Granovetter's model assumes an 'all-to-all' coupling, e.g. that the behaviour of individuals is determined by their threshold and the entire crowd, rather than just those in their immediate vicinity. More interesting results come from Watts (2002), whose models consider individuals to be influenced by a subset of the population. Each individual is modelled as a node on a network, and the threshold of each node is the fraction of this subset who must take action before it will.

Watts examines 'cascades': “during which individuals in a population exhibit herdlike behaviour because they are making decisions based on the actions of other individuals rather than relying on their own knowledge of the problem" (2002, 5766). Cascades are a class of 'contagion problems' which occur across diverse social (e.g. riots), economic, and physical systems. Via abstract models Watts was able to ascertain precise conditions "under which an enormous cascade will be triggered by a single domino [i.e. a 'perturbation']", as well as developing an understanding of the likelihood, size, and the risk factors which determines the network's vulnerability (Strogatz 2003, 266). Importantly, Watts maintains that "some generic features of cascades can be explained in terms of the connectivity of the network by which influence is transmitted between individuals" (2002, 5766 emphasis mine). A cascade depends less on the quantity of individual nodes that are vulnerable to the perturbation, and more on whether these vulnerable node are connected to one another. If they are, then there exists a 'vulnerable cluster' which, if perturbed, will generate the necessary momentum to trigger a global cascade.

More interestingly, differing levels of connectivity will result in the network reacting differently to perturbations that are, a priori, indistinguishable from one another. Two distinct 'tipping points' exist. Cascades cannot occur if the network is too sparsely connected; the effects of a perturbation remain local. The first tipping point occurs when these localities are connected, thereby making possible global cascades. However, a second tipping point occurs when as the network continues to increase in connectivity: because the behaviour of a particular node is determined by a sufficient proportion of those nodes to which it is connected, greater network connectivity results in a 'dilution effect' where individual nodes becomes more stable as the amount of their neighbours necessary to reach their threshold increases (Watts 2002; see also Strogatz 2003, 266-7). Two regions of stability therefore exist across the space of connectivity: "When the network of interpersonal influences is sufficiently sparse, the propagation of cascades is limited by the global connectivity of the network; and when it is sufficiently dense, cascade propagation is limited by the stability of the individual nodes" (Watts 2002, 5771).

If, following Hayek, we consider individuals as foci in a network of relationships, then certain economic phenomena might be fruitfully reconceived as patterns of activity propagating through the network: they arise from individuals connecting with one another, but receive elegant explanation in terms of the connections themselves. 


\subsection{Spontaneous order}

My aim in this paper has been to demonstrate how 'true individualism' enables a Gestalt switch from 'local' individuals to emergent, 'global' patterns. I stated that the justification for adopting an alternative perspective probably cannot be established a priori, but only demonstrated via further research (beyond the scope of this paper). Nevertheless, I will briefly outline three avenues of research which might be conducted from a 'system-level' perspective.

Optimisation: The 'travelling salesman program' presents us with a salesman who must visit an arbitrary number of cities before returning to their point of departure. It does not matter in which order the cities are visited and each city need only be visited once. The problem is to determine the 'optimal', i.e. shortest or least-costly, route that visits all cities. One method for finding the answer to this problem is 'brute force', i.e. examining all possible permutations then selecting the least-costly route. This approach is untenable: the number of possible routes increases exponentially as the number of cities increases, rendering brute force practically useless for anything above a small number of cities. In technical terminology, this problem is 'NP-hard'.

Although presented as a route-planning problem, it is applicable across disparate areas, e.g. microcircuitry component placement, neural connectivity, and ant trail recruitment. Natural systems appear to employ extremely efficient optimisation strategies. Significantly, these strategies are highly decentralised.

The foraging behaviour of ants (see Beckers et al. 1992) is both extremely effective at selecting optimal routes to food sources and extremely adaptable in dynamic environments (cf. Hayek's example of a path, above). Ants accomplish this by laying pheromone trails as they move, and these pheromones attract more ants who in turn lay more pheromones. The pheromones decay over time, and therefore the attractiveness of longer routes decreases faster than shorter routes. Additionally - and crucially selection of shorter routes is autocatalytic: as ants are attracted to the greater relative concentration of pheromone on the shorter route, they also increase the pheromone concentration, creating a self-reinforcing positive feedback loop. The ants' autocatalytic optimisation method has been drawn upon by software engineers to create optimisation algorithms (see Dorigo and Gambardella 1997), and is a key insight in 'swarm intelligence', influencing other fields such as robotics and computer science (see Bonabeau and Theraulaz 2000).

In neuroscience, another optimisation problem occurs. Yet, nature appears to have produced 'the best of all possible brains': the brain's long range connections are "a critically constrained resource", and yet "[n]euroconnectivity architecture sometimes shows virtually perfect network optimisation, rather than just network satisficing" (Cherniak 2012, 361). Instead of viewing such efficient organisation as written into the genome over a long period of evolution, Cherniak proposes that this optimisation emerges 'for free, directly from physics' and explores how basic physical processes interact with the genome to achieve optimal neural structure (see 2005). 
Organisation of a production structure (and the related issue of calculation ${ }^{24}$ ) appears to be - in part - an optimisation problem: the factors of production must be 'connected', but these factors are heterogenous (it is not possible to connect anything to anything else). This problem is far more difficult than the travelling salesman problem. An interesting question is therefore to what extent money and the price mechanism effect optimisation via decentralised, autocatalytic, and highly adaptable activity, and therefore to what extent the price mechanism instantiates more general principles underlying 'spontaneous order' in complex systems.

Stigmergy: Hülsmann (1997) is - to my knowledge - correct to say that, thus far, Hayekians have not detailed how the price mechanism effects coordination and transmits information. Stigmergy is a concept that has the potential to offer a formalisation (and modification?) of Hayek's insights concerning how the price mechanism achieves "the utilisation of knowledge which is not given to anyone in its totality" (1945, 78).

Without any central direction, ants and termites build extremely sophisticated structures and are able to reshape their constructions in response to changing conditions, e.g. increasing population, temperature changes, etc. (see Khuong et al. 2016). This intricate coordination is accomplished via stigmergy, ${ }^{25}$ i.e. indirect communication via the modification of the local environment to influence the actions of others at a later time. In the case of termites, nests are built from mud balls impregnated with pheromones: a randomly placed mudball induces other termites to deposit mudballs at the same location, creating columns which are joined by arches as the concentration of pheromones in each of the columns causes the termites working on neighbouring columns to build toward one another. Stigmergy has been recognised as an elegant mechanism by engineers, notably in 'collective robotics' (see Beckers et al. 1994).

As Clark emphasises, stigmergy is complementary to the philosophical themes explored above: "computational power and expertise is spread across a heterogeneous assembly of brains, bodies, and artefacts, and other external structures" (1997, 77). Stigmergy also appears to have been anticipated by Hayek in his discussion of the price mechanism and the question of "how to

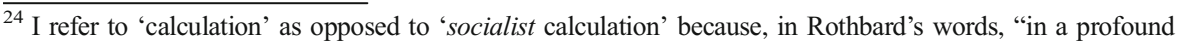
sense, the theory is not about socialism at all! Instead, it applies to any situation where one group has acquired control of the means of production over a large area - or, in a strict sense, throughout the world" (Rothbard $1976,823-4)$. Hoppe $(1996,144)$ is confused on this point, claiming the calculation problem is particular to socialism (defined as a social order absent private property) and that other 'collectives', e.g. clubs, firms, and families, are unaffected despite their 'central planning'. Hoppe is incorrect: absence of private property is a sufficient condition for the calculation problem, but it is not a necessary condition. The calculation problem may arise within an anarcho-capitalist social order (where all resources are privately owned). As Rothbard $(1976,824)$ notes, the calculation problem effectively limits a firm's possibilities for expansion: as a firm increases in size its ability to internally coordinate its activities decreases due to its inability to generate prices between its various divisions (it is effectively in the same situation as a socialist central planning board). Interesting topics which, to my knowledge, have not yet been addressed in detail are: under what formal conditions does the calculation problem arise and to what intensity and degree?

25 Deriving from the Greek 'stigma' ('goad') and 'ergon' ('work'), and capturing the notion of being induced to work by the product of work (see Beckers et al. 1994).
} 
dispense with the need for conscious control and how to provide inducements which will make the individuals do the desirable things without anyone telling them what to do" $(1945,88$ emphasis mine $){ }^{26}$

Combining stigmergy with emergence: individuals' actions may transform their environment, and these transformations may serve as signals - and means of connecting - to other individuals. The price system thereby permits a massive increases in the economy's connectivity, and enables a means by which individuals' knowledge of time and place may be utilised ${ }^{27}$ and by which individuals' actions may be coordinated.

Recurrent neural networks are a class of devices that may prove capable of modelling this process. A recurrent network retains certain information and feeds it back into the system alongside with new inputs. Hence, the network's output is a function of both new input and prior values. Within a monetary economy, we might conceive prices of goods of lower orders being values that are 'fed back', via the 'entrepreneurial function', to determine alongside new inputs the valuations of goods of higher order and the factors of production.

Computational Complexity: Hayek's insight that prices transmit information might be extended. Viewing economies as computational systems could permit the classification of (abstract) economic systems based on their 'power', i.e. their ability to generate certain degrees of complexity. Economic development need not be gradual, compounding improvements, but may also be saltational, i.e. leaps from one type of organisation to another. For example, monetary economies are undoubtedly more complex than gift economies. It is possible to create and maintain capital goods in a gift economy, but this process is far more efficient in a monetary system. The interesting questions are whether and to what extent the transition ${ }^{28}$ from a gift to monetary economy alters the formal 'space' of possibilities for a given economy, and whether this may be accounted for in terms of a more powerful form of information processing.

There is a possible analogy here to the Chomsky-Schützenberger hierarchy in formal linguistics and computer science. This is a containment hierarchy classifying formal grammars based on the restrictions on the types of rules they may employ and the types of automata that recognise them (see Chomsky 1959b, and Chomsky and Schützenberger 1963). More restricted grammars and less computationally powerful devices, e.g. finite state automata, are incapable of generating certain structures generated by grammars subject to less restrictions and more computationally powerful automata, e.g. universal Turing machines. Similarly, we might question where there exist formal conditions determining the computational complexity of an economy.

\footnotetext{
${ }^{26}$ Admittedly, Hayek also contrasted human civilisation with the 'states' of termites $(1945,89)$.

${ }^{27}$ Hoppe has a bizarre interpretation of this particular point. Hoppe accepts that individuals possess 'private' knowledge of time and place. However, because prices are public knowledge ("prices - qua objective exchange ratios - are real events") and because Hayek ascribes the calculation problem to the inability to utilise private knowledge, Hoppe concludes that Hayek's position entails that the calculation problem has nothing to do with prices $(1996,146)$. Particular knowledge of time and place is crucial for forming genuine prices, but to my knowledge Hayek never claims their relation is identity. Indeed, Hayek states exactly the contrary: it is significant that we do not know the cause of a price movement $(1945,86)$. That their relation is not identity does not preclude prices being generated from knowledge of time and place.

${ }^{28}$ A conjecture: this is a phase transition.
} 


\section{Conclusions}

In Discourse on the Method, Descartes expressed his frustration with "those meddlesome and restless characters who, called neither by birth nor by fortune to the management of public affairs, are yet forever thinking up some new reform" (CSM I, AT VI 14). Such characters neither understand that it would be "unreasonable" to "reform a state by... overturning it in order to set it up again" nor appreciate that the customs of a people have "prevented or imperceptibly corrected many imperfections" in public institutions (CSM I, AT VI 13-4). Superficially, this seems to resonate with Hayek's contention that:

The recognition of the insuperable limits to his knowledge ought indeed to teach the student of society a lesson of humility which should guard him against becoming an accomplice in men's fatal striving to control society - a striving which makes him not only a tyrant over his fellows, but which may well make him the destroyer of a civilisation which no brain has designed but which has grown from the free efforts of millions of individuals. (Hayek 1974)

However, the resonance is only superficial. Whereas Hayek believed reasoning to be a social process, Descartes held that "a majority vote is worthless as a proof of truths that are at all difficult to discover; for a single man is much more likely to hit upon them than a group of people" (CSM I, AT VI 16 emphasis mine). Drawing an analogy with craftsman and architects, whose works Descartes believed superior when they were the product of a single person, Descartes claimed that a society which from its birth "observed the basic laws laid down by some wise law-giver" would have superior governance to a society which created legislation only in response to "the inconvenience of crimes and quarrels" (CSM I, AT VI 12). Hayek believed, in stark contrast, that "society is greater than the individual only in so far as it is free. In so far as it is controlled or directed, it is limited to the powers of the individual minds which control or direct it" $(1946,32)$.

A deep philosophical division exists between Hayek and Descartes, which Hayek identified and characterised as a distinction between true and false individualism. In this paper I took up this distinction, using Descartes as a foil to distinguish the 'Hayekian' approach from Misesian-Rothbardian praxeology.

Despite Hayek's belief that Mises "helped us to understand something which we have not designed" and had "largely emancipated himself from that rationalistconstructivist starting point", Hayek felt that the "task is still to be completed" (1978, xxiv). Accordingly, I presented a number of aspects of praxeology that are shared with Cartesian rationalism: intuition-deduction; reductionism; judgement; dualism. These 'Cartesian' aspects result in praxeologists adopting a strict methodological individualism, which in turn shapes their view on economic processes:

Knowledge is an individual process, by which each individual entrepreneur learns as much as he can about the largely qualitative nature of the market he faces... This process necessarily goes on only in the mind of each individual. On the other hand, the prices provided by the market, especially the prices of means of production, are a social process, available to all participants, by which the entrepreneur is able to appraise and estimate future costs and prices. (Rothbard 2011, 188) 
The 'Hayekian' alternative (N.B. not Hayek's alternative) draws on research in cognitive science to call into question praxeology's Cartesian presuppositions: a dualist characterisation of cognition is inaccurate if mind is a complex system encompassing brain, body, and world; robotics provides an illustration of how it is possible to have intelligence without accompanying judgement; where judgement is required, it is possible that judgement is only possible due to symbols that encapsulates information generated by the dynamics of a wider system; certain economic phenomena may occur due to the connectivity of a network of individuals, and consequently intuition and deduction may be insufficient explain such phenomena. Accordingly, it may well be fruitful to adopt a system-level perspective. This could open new avenues of research, of which I suggested three: optimisation; stigmergy; computational complexity.

Acknowledgments Thanks to Mr. William Peden and Mr. Daniel Pryor for feedback and the initial impetus to address this topic. Thanks also to Prof. David Howden for discussion of these ideas following an initial presentation of them.

Open Access This article is distributed under the terms of the Creative Commons Attribution 4.0 International License (http://creativecommons.org/licenses/by/4.0/), which permits unrestricted use, distribution, and reproduction in any medium, provided you give appropriate credit to the original author(s) and the source, provide a link to the Creative Commons license, and indicate if changes were made.

\section{References}

Adessi, E., \& Rossi, S. (2011). Tokens improve capuchin performance in the reverse-reward contingency task. Proceedings of the Royal Society: Biological Sciences, 278, 849-854.

Alanen, L. (2014). The second meditation and the nature of the human mind. In D. Cunning (Ed.), The Cambridge companion to Descartes' meditations. Cambridge: Cambridge University Press.

Anderson, J. R., Hattori, Y., \& Fujita, K. (2008). Quality before quantity: rapid learning of reversereward contingency by capuchin monkeys (Cebus apella). Journal of Comparative Psychology, 122(4), 445-448.

Ariely, D., \& Wallsten, T. S. (1995). Seeking subjective dominance in multidimensional space: an explanation of the asymmetric dominance effect. Organizational Behavior and Human Decision Processes, 63(3), 223-232.

Beckers, R., Deneubourg, J. L., \& Goss, S. (1992). Trails and U-turns in the selection of a path by the ant Lasius niger. Journal of Theoretical Biology, 159, 397-415.

Beckers, R., Holland, O. E., \& Deneubourg, J. L. (1994). From local actions to global tasks: stigmergy and collective robotics'. Artificial life IV: proceedings of the fourth international workshop on the synthesis and simulation of living systems. Cambridge: MIT Press.

Bonabeau, E., \& Theraulaz, G. (2000). Swarm smarts. Scientific American, 282(3), 76-77.

Boysen, S. T., Berntson, G. G., Hannan, M. B., \& Cacioppo, J. T. (1996). Quantity-based inference and symbolic representations in chimpanzees (Pan troglodytes). Animal Behaviour Processes, 22(1), 76-86.

Brooks, R. A. (1985). A robust layered control system for a mobile robot. Massachusetts Institute of Technology Artificial Intelligence Laboratory A. I. Memo 864.

Brooks, R. A. (1990). Elephants Don't play chess. Robotics and Autonomous Systems, 6, 3-15.

Brooks, R. A. (1991). Intelligence without reason. Massachusetts Institute of Technology Artificial Intelligence Laboratory A. I. Memo 1293.

Caldwell, B. J. (1992). Hayek the falsificationist? A refutation. Research in the History of Economic Thought and Methodology, 10, 1-15.

Cherniak, C. (2005). Innateness and brain wiring optimisation: non-genomic nativism. In A. Zilhao (Ed.), Cognition, evolution, and rationality. London: Routledge.

Cherniak, C. (2012). Neural wiring optimisation. In M. A. Hofman \& D. Falk (Eds.), Evolution of the primate brain: from neuron to behaviour. Amsterdam: Elsevier. 
Chomsky, N. (1956). Three models for the description of language. IRE Transactions on Information Theory, 2, 113-124.

Chomsky, N. (1959a). A review of B. F. Skinner's verbal behaviour. Language, 35(1), $26-58$.

Chomsky, N. (1959b). On certain formal properties of grammars. Information and Control, 2, 137-167.

Chomsky, N. (1965). Aspects of the theory of syntax. Cambridge: MIT Press.

Chomsky, N. (1971). The case against B. F. Skinner. The New York Review of Books.

Chomsky, N. (2005). New horizons in the study of language and mind. Cambridge: Cambridge University Press.

Chomsky, N., \& Schützenberger, M. (1963). The algebraic theory of context free languages. In P. Braffort \& D. Hirschberg (Eds.), Computer programming and formal systems. Amsterdam: North-Holland Publishing Company.

Clark, A. (1997). Being there: putting brain, body, and world together again. Oxford: Blackwell.

Clark, A. (1998). Magic words: how language augments human computation. http://www.philosophy.ed.ac. uk/people/clark/pubs/magic.pdf. Accessed: 15 April 2016.

Clark, A. (2001). Mindware: an introduction to the philosophy of cognitive science. Oxford: Oxford University Press.

Clark, A. (2011). Supersizing the mind: embodiment, action, and cognitive extension. Oxford: Oxford University Press.

Cordemoy, G. (1668). A philosophical discourse concerning speech. Royal Society: Conformable to the Cartesian Principles.

Cottingham, J. (2008). Cartesian reflections: essays on Descartes' philosophy. Oxford: Oxford University Press.

Descartes, R. (1984). In J. Cottingham, R. Stoothoff, D. Murdoch [CSM], \& A. Kenny (Eds.), Philosophical writings of Descartes. 3 Vols. Cambridge: Cambridge University Press.

Dorigo, M., \& Gambardella, L. M. (1997). Ant colonies for the travelling salesman problem. Biosystems, 43, 73-81.

Everett. D. L. (2005). Cultural Constraints on Language and Cognition in Pirahã: Another Look at the Design Features of Human Language. http://pnglanguages.org/americas/brasil/PUBLCNS/ANTHRO/PHGrCult.pdf. Accessed: 15 April 2016.

Fodor, J. (1980). Methodological solipsism considered as a research strategy in cognitive psychology. Brain and Behavioural Sciences, 3, 63-73.

Frank, M. C., Fedorenko, E., Gibson, E. (2008a). Language as a cognitive technology: english-speakers match like pirahã when you don't let them count. 30th Annual Meeting of the Cognitive Science Society in Washington DC.

Frank, M. C., Everett, D. L., Fedorenko, E., Gibson, E. (2008b). Number as a cognitive technology: evidence from pirahã language and cognition. http://www.letras.ufrj.br/poslinguistica/recursion/papers/18-frank-et-al.pdf. Accessed: 15 April 2016.

Galileo (2012) Selected writings. Shea WR, Davie M (trans.), Oxford University Press, Oxford

Gibson, J. J. (1979). The ecological approach to visual perception. London: Houghton Mifflin Company.

Gordon, D. (1996). The philosophical origins of Austrian economics. Auburn: Ludwig von Mises Institute.

Granovetter, M. (1978). Threshold models of collective behaviour. American Journal of Sociology, $83,1420-1443$.

Hayek FA (1945) 'The use of knowledge in society'. American Economic Review, XXXV(4):519-30. Reprinted in individualism and economic order, University of Chicago Press, Chicago.

Hayek, F. A. (1946). Individualism: true and false. In Individualism and economic order. Chicago: University of Chicago Press.

Hayek, F. A. (1974). 'The pretence of knowledge'. the official website of the nobel prize http://www. nobelprize.org/nobel_prizes/economic-sciences/laureates/1974/hayek-lecture.html. Accessed 25 October 2015.

Hayek, F. A. (1978). Foreword' to Ludwig von Mises' socialism: an economic and sociological analysis. Indianapolis: Liberty Classics.

Hayek, F. A. (2010). In B. Caldwell (Ed.), Studies on the abuse and decline of reason: texts and documents. Chicago: University of Chicago Press.

Heidegger M (2006) Being and Time. Macquarrie J, Robinson E (trans.), Blackwell, Oxford

Herbener, J. M. (1996). Calculation and the question of arithmetic. The Review of Austrian Economics, 9(1), $151-162$.

Hodgson, G. M. (2007). Meanings of methodological individualism. Journal of Economic Methodology, $14(2), 211-226$. 
Hoeffler, S., \& Ariely, D. (1999). Constructing stable preferences: a look into dimensions of experience and their impact on preference stability. Journal of Consumer Psychology, 8(2), 113-139.

Hoppe, H. H. (1995). Economic science and the Austrian method. Auburn: Ludwig von Mises Institute.

Hoppe, H. H. (1996). Socialism: a property or knowledge problem? Review of Austrian Economics, 9(1), 143-149.

Hornsby, J. (2006). Physicalist thinking and conceptions of behaviour. In J. L. Bermúdez (Ed.), Philosophy of psychology: contemporary readings. London: Routledge.

Huber, J., Payne, J. W., \& Puto, C. (1982). Adding asymmetrically dominated alternatives: violations of regularity and the similarity hypothesis. Journal of Consumer Research, 9(1), 90-98.

Hülsmann, J. G. (1997). Knowledge, judgement, and the use of property. Review of Austrian Economics, $10(1), 23-48$.

Hülsmann, J. G. (2006). Methodological individualism is not the method of economics. In M. Laine \& J. G. Hülsmann (Eds.), L'Homme libre: festschrift in honour of Pascal Salin. Paris: Les Belles Lettres.

Jackendoff, R. (2003). Foundations of language: brain. Meaning: Grammar, Evolution, Oxford University Press, Oxford.

Kant, I. (1996). Critique of pure reason. Pluhar WS (trans.), Hackett, Indianapolis.

Khuong, A., Gautrais, J., Perna, A., Sbaï, C., Combe, M., Kuntz, P., Jost, C., \& Theraulaz, G. (2016). Stigmergic construction and Topochemical information shape ant Nest architecture. Proceedings of the National Academy of Sciences, 113(5), 1303-1308.

Kinsella, S. N. (1999). Knowledge, calculation, conflict, and law. The Quarterly Journal of Austrian Economics, 2(4), 49-71.

Leibniz GW (1704) New essays on human understanding. Bennett J (trans.), http://www.earlymoderntexts. com/assets/pdfs/leibniz1705book1.pdf. Accessed 15 April 2016.

Lewis, P. (2012). Emergent properties in the work of F. A. Hayek. Journal of Economic Behavior and Organization, 82, 368-378.

Locke, J. (2014). An essay concerning human understanding. Ware: Wordsworth Editions.

Malt, A. J. (2013). Psyche and praxis: extended cognition and the Austrian school. The Journal of Prices and Markets, 1(2), 6-14.

Markie, P. (2015). 'Rationalism vs. Empiricism'. Stanford Encyclopaedia of Philosophy. Zalta EN (ed.). http://plato.stanford.edu/entries/rationalism-empiricism/. Accessed 15 April 2016.

Mataric, M. J. (1990). Navigating with a rat brain: A neurobiologically inspired model for robot spatial behaviour. Proceedings of the First International Conference on Simulation of Adaptive Behaviour, 169-175.

Merleau-Ponty, M. (2006). Phenomenology of perception. Smith C (trans.), Routledge, Oxford.

Mises, L. (1951). Socialism: an economic and sociological analysis. New Haven: Yale University Press.

Mises, L. (1962). The ultimate Foundation of Economic Science: an essay on method, D. Princeton: van Nostrand Company.

Mises, L. (1998). Human action: a treatise on economics (Scholar's edition). Auburn: Ludwig von Mises Institute.

O'Connor, T., Wong, H. Y. (2015). 'Emergent properties'. The Stanford Encyclopaedia of Philosophy. Zalta EN (ed.) http://plato.stanford.edu/archives/sum2015/entries/properties- emergent/ Accessed: 15 April 2016.

Oppy, G., Dowe, D. (2011). The turing test. The Stanford Encyclopaedia of Philosophy. Zalta EN (ed.) http://plato.stanford.edu/archives/spr2011/entries/ turing-test/ Accessed: 15 April 2016.

Payne, J. W., Bettman, J. R., \& Johnson, E. J. (1992). Behavioural decision research: a constructive processing perspective. Annual Review of Psychology, 43, 87-131.

Rothbard, M. N. (1960). The mantle of science. Scientism and Values. Schoeck H, Wiggins JW (eds.). D. van Nostrand, Princeton. Reprinted in Economic Controversies. Ludwig von Mises Institute, Auburn, Al.

Rothbard, M. N. (1961). What is the Proper Way to Study Man? The National Book Foundation. Reprinted in Economic Controversies, Ludwig von Mises Institute, Auburn Al.

Rothbard, M. N. (1973). Praxeology as the method of the social sciences. Phenomenology and the social sciences. Natanson M (ed.). Northwestern University Press, Evanston. Reprinted in Economic Controversies, Ludwig von Mises Institute, Auburn, Al.

Rothbard, M. N. (1976). Ludwig von mises and economic calculation under socialism. The Economics of Ludwig von Mises. Kansas City: Sheed and Ward. Reprinted in Economic Controversies. Ludwig von Mises Institute, Auburn Al.

Rothbard, M. N. (2009). Man economy and state: a treatise on economic principles with power and market: government and the economy. Auburn: Ludwig von Mises Institute. 
Rothbard, M. N. (2011). The present state of Austrian economics. Auburn: Economic Controversies. Ludwig von Mises Institute.

Rowlands, M. (1995). Against methodological solipsism: the ecological approach. Philosophical Psychology, $8(1), 5-24$.

Selgin, G. (1990). Praxeology and understanding: an analysis of the controversy in Austrian economics. Auburn: Ludwig von Mises Institute.

Simonson, I., \& Tversky, A. (1992). Choice in context: tradeoff contrast and extremeness aversion (pp. 281295). XXIX: Journal of Marketing Research.

Slowik, E. (2014). Descartes' physics. The Stanford Encyclopaedia of Philosophy, Zalta EN (ed.) http://plato.stanford.edu/archives/sum2014/entries/descartes-physics/ Accessed 15 April 2016.

Smith, B. (1990). The question of a priorism. Auburn: Austrian Economics Newsletter, Ludwig von Mises Institute.

Strogatz, S. (2003). Sync: the emerging science of spontaneous order. London: Penguin.

Turing, A. M. (1950). Computing machinery and intelligence. Mind, 59, 433-460.

Tversky, A., \& Simonson, I. (1993). Context-dependent preferences. Management Science, 39(10), 1179-1189.

Van Gelder, T. (1995). What might cognition be if not computation? The Journal of Philosophy, 92(7), 345-381.

Van Gelder, T. (1998). The dynamical hypothesis in cognitive science. Behavioral and Brain Sciences, 21, 615-665.

Watts, D. J. (2002). A simple model of global cascades on random networks. Proceedings of the National Academy of Sciences USA, 99, 5766-5771.

Webb, B. (1996). A cricket robot. Scientific American, 275, 62-67.

Wittgenstein, L. (1975). Philosophical remarks. Hargreaves $R$, White R (trans.). Oxford: Basil Blackwell.

Wittgenstein, L. (2001). Philosophical investigations. Anscombe GEM (trans.). Oxford: Blackwell. 